\title{
Tree nut phytochemicals: composition, antioxidant capacity, bioactivity, impact factors. A systematic review of almonds, Brazils, cashews, hazelnuts, macadamias, pecans, pine nuts, pistachios and walnuts
}

\author{
Bradley W. Bolling ${ }^{1}$, C.-Y. Oliver Chen ${ }^{2}$, Diane L. McKay ${ }^{2}$ and Jeffrey B. Blumberg ${ }^{2 *}$ \\ ${ }^{1}$ Department of Nutritional Sciences, University of Connecticut, 3624 Horsebarn Road Extension, Unit 4017, Storrs, \\ CT 06269, USA \\ ${ }^{2}$ Antioxidants Research Laboratory, Jean Mayer USDA Human Nutrition Research Center on Aging, Tufts University, \\ 711 Washington Street, Boston, MA 02111, USA
}

\section{Abstract}

Tree nuts contain an array of phytochemicals including carotenoids, phenolic acids, phytosterols and polyphenolic compounds such as flavonoids, proanthocyanidins (PAC) and stilbenes, all of which are included in nutrient databases, as well as phytates, sphingolipids, alkylphenols and lignans, which are not. The phytochemical content of tree nuts can vary considerably by nut type, genotype, pre- and post-harvest conditions, as well as storage conditions. Genotype affects phenolic acids, flavonoids, stilbenes and phytosterols, but data are lacking for many other phytochemical classes. During the roasting process, tree nut isoflavones, flavanols and flavonols were found to be more resistant to heat than the anthocyanins, PAC and trans-resveratrol. The choice of solvents used for extracting polyphenols and phytosterols significantly affects their quantification, and studies validating these methods for tree nut phytochemicals are lacking. The phytochemicals found in tree nuts have been associated with antioxidant, anti-inflammatory, anti-proliferative, antiviral, chemopreventive and hypocholesterolaemic actions, all of which are known to affect the initiation and progression of several pathogenic processes. While tree nut phytochemicals are bioaccessible and bioavailable in humans, the number of intervention trials conducted to date is limited. The objectives of the present review are to summarise tree nut: (1) phytochemicals; (2) phytochemical content included in nutrient databases and current publications; (3) phytochemicals affected by pre- and post-harvest conditions and analytical methodology; and (4) bioactivity and health benefits in humans.

Key words: Antioxidants: Polyphenols: Phytochemicals: Tree nuts

Phytochemical databases with tree nuts

\section{Definition of phytochemicals}

The term 'phytochemical' broadly refers to all plantderived chemicals. Hence, macronutrients such as plant carbohydrates (including dietary fibre), lipids and proteins could be categorised as phytochemicals. However, for the purposes of the present report, we use the term 'phytochemical' to refer to small non-essential nutrients with putative health-promoting actions. We categorise phytochemicals into six broad classes: alkaloids, organosulfurs, phenolics, carbohydrates, non-nutritive proteins and lipids (Fig. 1).

\section{Tree nut phytochemical classes}

Tree nuts contain the majority of phytochemical classes. To date, we are not aware of reports of organosulfurs or non-nutritive proteins (for example, antioxidant enzymes) in tree nuts. The present report examines the content of total phenols, flavonoids, proanthocyanidins (PAC), stilbenes, phytosterols, carotenoids and other classes in tree nuts.

Total phenols. Phenolics are a major phytochemical class, and include the broad term 'polyphenols', meaning a molecule with one or more phenolic groups. The Folin-Ciocalteu assay is commonly used as a non-specific measure of 'total phenols' or 'total polyphenols'. However,

\footnotetext{
Abbreviations: CRP, C-reactive protein; DPPH, 2,2-diphenyl-2-picrylhydrazyl; eBASIS, BioActive Substances in Food Information System; EuroFIR, European Food Information Resource; FRAP, ferric-reducing antioxidant power; GAE, gallic acid equivalent; HT, hydrolysable tannin; ICAM-1, intercellular adhesion molecule-1; LC, liquid chromatography; ORAC, oxygen radical absorbance capacity; PAC, proanthocyanidin; PE, Phenol-Explorer; SR-23, USDA National Nutrient Database for Standard Reference, release 23; TAC, total antioxidant capacity; USDA, US Department of Agriculture; VCAM-1, vascular cell adhesion molecule-1.
} 


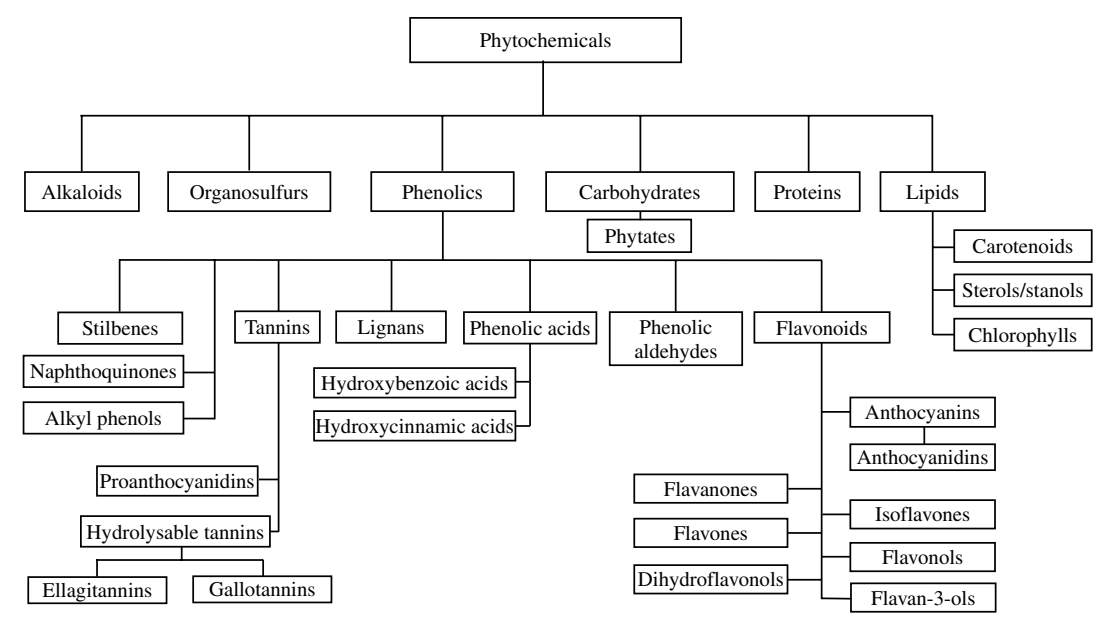

Fig. 1. Organisation of phytochemical classes.

the assay reagent also reacts with sugars, ascorbic acid, aromatic amines and other non-phenolic substances, many of which are present in tree nuts. Thus, total phenols can be regarded as only an approximation of polyphenol content in tree nuts.

Flavonoids. Flavonoids are a subclass of phenolics, characterised by a chalcone $\mathrm{C}_{6} \mathrm{C}_{3} \mathrm{C}_{6}$ structure, and include the main six subclasses: flavonols, flavones, flavanones, flavan-3-ols, anthocyanidins and isoflavones (Fig. 2). Flavan-3-ols, flavonols and anthocyanins are the main flavonoids present in nuts, while flavanones and isoflavones are found in lesser amounts.

Proanthocyanidins. PAC are flavan-3-ol oligomers linked through carbon-carbon bonds. Type A PAC consist of a $\mathrm{C}_{4}$ to $\mathrm{C}_{6}$ or $\mathrm{C}_{8}$ interflavan bond and a $\mathrm{C}_{2}$-ether bond to the flavanol extension. Type $\mathrm{B}$ PAC have single $\mathrm{C}_{4}$ to $\mathrm{C}_{6}$ or $\mathrm{C}_{8}$ interflavan bonding (Fig. 2). Tree nut PAC are comprised mainly of $(+)$-catechin and $(-)$-epicatechin, but also include afzelechin (almonds) and epigallocatechin (hazelnuts, pecans, pistachios) ${ }^{(1-3)}$. Among tree nuts, the A-type PAC have been found only in almonds. The majority of tree nut PAC are highly polymerised (>10-mers) ${ }^{(1)}$.

Stilbenes. Stilbenes are similar to chalcones, as their structure consists of two phenyl groups interconnected through an ethene bond. The ethene bond is mainly in the trans configuration, but may revert to the cis form on exposure to light or heat. Resveratrol and piceid are the only stilbenes thus far identified in tree nuts, and are found in pistachios (Fig. 2).

Phytosterols. Phytosterols are lipophilic plant-synthesised steroids. Sterols consist of three six-carbon rings, one five-carbon ring attached to an aliphatic chain, and a $\mathrm{C}_{3}$ hydroxyl group on the $\mathrm{A}$ ring ${ }^{(4)}$. Sterol esters have a fatty acid esterified to the $\mathrm{C}_{3}$ hydroxyl group ${ }^{(4)}$. Sterols and stanols are differentiated by an alkene bond at the $\mathrm{C}_{1}$ position on the $\mathrm{B}$ ring. Tree nut phytosterols are mainly composed of $\beta$-sitosterol (Fig. 2).
Carotenoids. Carotenoids are polyisoprenoids with differing degrees of conjugated double bonds (Fig. 2). In contrast to other plant foods, tree nuts contain very low amounts of carotenoids with $\alpha$ - and $\beta$-carotene, $\beta$-cryptoxanthin, lutein and zeaxanthin found in $\mu \mathrm{g} / 100 \mathrm{~g}$ concentrations when present at all. Pistachios present a modest exception, with a mean $\beta$-carotene and lutein content of 0.21 and $4.4 \mathrm{mg} / 100 \mathrm{~g}$ dry weight, respectively ${ }^{(5)}$.

Other phytochemical classes. Tree nuts also contain phytates and the lipid subclasses of chlorophylls and sphingolipids. Other phenolic constituents consist of lignans, alkylphenols and hydrolysable tannins (HT). Walnuts also contain the alkaloid melatonin and the naphthoquinone juglone (Fig. 2).

\section{Phytochemical databases}

A number of databases report the phytochemical content of foods (Table 1). In the present report we analysed the US Department of Agriculture (USDA) flavonoid, isoflavone, PAC and standard reference databases, along with the Phenol-Explorer and European Food Information Resource (EuroFIR) databases. We excluded the remaining databases due to inactivity, lack of quantitative information for tree nut phytochemicals or incomplete citations of data sources. Also, we did not analyse international food composition databases equivalent to the USDA Standard Reference, which may include carotenoid or sterol information for tree nuts

US Department of Agriculture phytochemical databases. The USDA Nutrient Data Laboratory (Beltsville, MD, USA) established databases for total phenols, flavonoids, isoflavones and PAC ${ }^{(6-9)}$. The Nutrient Data Laboratory maintains these databases and encourages submission of data directly to their laboratory. In general, the USDA databases report phytochemical mean, minimum and maximum contents, a confidence code that judges the reliability 
<smiles>O=c1c(O)c(-c2ccccc2)oc2ccccc12</smiles>

Flavonol<smiles>OC1Cc2ccccc2OC1c1ccccc1</smiles>

Flavan-3-ol<smiles>O=c1cc(-c2ccccc2)oc2ccccc12</smiles>

Flavone<smiles>Oc1cc2ccccc2[o+]c1-c1ccccc1</smiles>

Anthocyanidin<smiles>O=C1CC(c2ccccc2)Oc2ccccc21</smiles>

Flavanone<smiles>O=c1c(-c2ccccc2)coc2ccccc12</smiles>

Isoflavone<smiles>O=C1C=CC(=O)c2c(O)cccc21</smiles>

Juglone<smiles>Oc1ccc(/C=C/c2cc(O)cc(O)c2)cc1</smiles>

Trans-resveratrol<smiles>CC1c2c(O)cc(O)cc2OC(c2ccc(O)c(O)c2)C1O</smiles><smiles>Cc1c(O)cc(O)c2c1OC(c1ccc(O)c(O)c1)C(O)C2C</smiles><smiles>Cc1c(O)cc(O)c2c1OC(c1ccc(O)c(O)c1)C(O)C2</smiles>

B-type proanthocyanidins<smiles>CC1=C(/C=C/C(C)=C/C=C/C(C)=C/C=C/C=C(C)/C=C/C=C(C)/C=C/C2=C(C)CCCC2(C)C)C(C)(C)CCC1</smiles>

$\beta$-Carotene<smiles>CC1=C(/C=C/C(C)=C/C=C/C(C)=C/C=C/C=C(C)/C=C/C=C(C)/C=C/C2=C(C)C[C@@H](O)CC2(C)C)C(C)(C)C[C@H](O)C1</smiles>

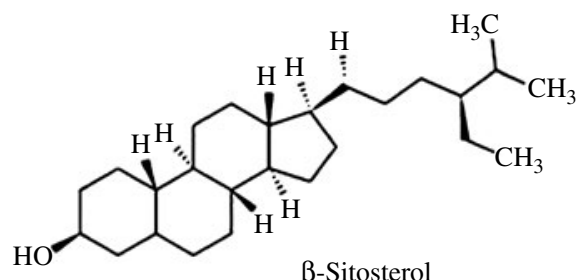

Lutein

Fig. 2. Major flavonoid classes and other representative phytochemicals present in tree nuts.

of the data, and the source of information. The USDA phytochemical databases are not frequently updated. For example, the USDA flavonoid database was released in 2003, and updated in 2007. Phytochemical content is reported as aglycone equivalents, which in some cases has been converted from glycoside equivalents. Thus, the phytochemical content of some tree nuts may not match values reported in the literature. This method facilitates

Table 1. Databases that include phytochemical or antioxidant content of foods

\begin{tabular}{lll}
\hline Database & Year updated & Relevant components \\
\hline USDA Flavonoid Database* $^{*}$ & 2007 & Flavonoids \\
USDA Isoflavone Database* & 2008 & Isoflavones \\
USDA Proanthocyanidin Database* & 2004 & PAC \\
USDA ORAC and Total Phenols Database* & 2007 & ORAC, TP \\
USDA National Nutrient Database for Standard Reference, release 22* & 2010 & Sterols, carotenoids \\
Phenol-Explorer* & Continuous & TP, PAC, flavonoids, phenolic acids, other polyphenols \\
University of Oslo FRAP Database* & 2010 & FRAP \\
EuroFIR: eBASIS* & Continuous & Flavonoids, others, biological activity of phytochemicals \\
Dr. Duke's Phytochemical and Ethnobotanical Databases & 1996 & Polyphenols, other \\
FooDB Food Component Database & Continuous & Food additives \\
KNApSAcK & Continuous & Metabolites of food components \\
Toxin and Toxin Target Database & Continuous & Food toxins and contaminants \\
DrugBank & Continuous & Nutraceuticals \\
Human Metabolome Database & Continuous & Food components and additives \\
www.metabolomics.jp & Continuous & Flavonoids and other metabolites
\end{tabular}

USDA, US Department of Agriculture; PAC, proanthocyanidins; ORAC, oxygen radical absorbance capacity; TP, total phenols; FRAP, ferric-reducing antioxidant power; EuroFIR, European Food Information Resource.

${ }^{*}$ Analysed in the present report. 
Table 2. Total phenols content of nine tree nuts reported in the US Department of Agriculture (USDA) ${ }^{(6)}$ and Phenol-Explorer ${ }^{(16)}$ databases

\begin{tabular}{lcc}
\hline Tree nut & $\begin{array}{c}\text { USDA } \\
\text { (mg GAE/100 mg) }\end{array}$ & $\begin{array}{c}\text { Phenol-Explorer } \\
\text { (mg GAE/100 mg) }\end{array}$ \\
\hline Almonds & 418 & 287 \\
Brazil nuts & 310 & 244 \\
Cashews & 269 & 233 \\
Hazelnuts & 835 & 687 \\
Macadamias & 156 & 126 \\
Pecans & 2016 & 1816 \\
Pine nuts & 68 & 58 \\
Pistachios & 1657 & 1420 \\
Walnuts, English & 1556 & 1576 \\
\hline
\end{tabular}

GAE, gallic acid equivalents.

combining data from studies using hydrolysis to remove glycosides from polyphenols. The post-harvest processing of tree nuts is not distinguished in these databases, but it should be noted that the flavonoid data are from commercial samples ${ }^{(10)}$.

US Department of Agriculture phytochemical databases: total phenols. The USDA Oxygen Radical Absorbance Capacity (ORAC) database includes the total phenol value of each tree nut (Table 2) ${ }^{(6)}$. The data are derived from only one study, with seven or eight samples for each tree nut. Pecans, pistachios and walnuts have the highest total phenol content, with 1556 to $2016 \mathrm{mg}$ gallic acid equivalents (GAE)/100 g.

US Department of Agriculture phytochemical databases: flavonoids. The USDA flavonoid database reports the flavan-3-ol, flavanone, flavonol and anthocyanin content of each tree nut (Table 3) ${ }^{(8)}$. Pecans, pistachios, almonds and hazelnuts have the highest reported flavonoid content, with 12 to $34 \mathrm{mg}$ flavonoids $/ 100 \mathrm{~g}$. The data for the USDA database are derived from only three studies and the number of samples ranged from 1 to 16. Therefore, the data populating the USDA flavonoid database are limited. Ideally, these values would be derived from multiple laboratories to arrive at reliable values for flavonoid content.

All tree nuts except for macadamias and Brazil nuts have flavonoid values listed in the USDA flavonoid database. In contrast, Yang et al. ${ }^{(11)}$ reported $107 \mathrm{mg}$ catechin equivalents/100 $\mathrm{g}$ in Brazil nuts, and $140 \mathrm{mg}$ catechin equivalents/100 $\mathrm{g}$ in macadamias, using a non-specific analytical technique. Therefore, more rigorous investigations into the flavonoid content of Brazil nuts and macadamias are warranted.

Flavan-3-ols, flavonols and anthocyanins are the main flavonoids in nuts. Cashews and pine nuts do not contain anthocyanins. Flavonols are also reported for almonds and pistachios, mainly as isorhamnetin and kaempferol for almonds and quercetin for pistachios. However, no studies are included in the database that measure isorhamnetin or kaempferol content in tree nuts other than almonds. Thus, a significant amount of phytochemical content remains uncharacterised from most tree nuts.

Pecans have the highest total flavonoid content among nuts at $34 \mathrm{mg} / 100 \mathrm{~g}$, consisting mostly of flavan-3-ols and anthocyanins. Hazelnuts and almonds also have an appreciable content of flavonoids with 18 and $15 \mathrm{mg} /$ $100 \mathrm{~g}$, respectively. Flavanones are only reported in almonds, but no studies included in the database have measured eriodictyol in the other tree nuts. Most confidence codes are A and B for all flavonoids and tree nuts, although an unidentified species of walnut received a $\mathrm{C}$ value for flavonoid data confidence.

US Department of Agriculture phytochemical databases: isoflavones. Last updated in 2008, the USDA isoflavone database contains entries for most tree nuts, except for macadamias and pine nuts ${ }^{(7)}$. To our knowledge, there are no studies examining isoflavone content of macadamias, but Kuhnle et al. ${ }^{(12)}$ reported $32 \mu \mathrm{g}$ isoflavones/ $100 \mathrm{~g}$ pine nuts. The isoflavone database includes daidzein, genistein and glycitein content and their sums, reported as 'total isoflavones'. Values for the isoflavones formononetin and coumestrol are also reported. Pistachios have the highest isoflavone content of nuts at $3.63 \mathrm{mg} / 100 \mathrm{~g}$ mainly as daidzein and genistein, more than 100-fold greater than levels of other nuts (Table 4). Only one or two samples have been analysed for the isoflavone data, and are derived from three references. The confidence codes for these data are mainly $\mathrm{C}$ and $\mathrm{D}$ values, but Brazil nuts received a $\mathrm{B}$ value. Therefore, more work is needed to quantify isoflavones in tree nuts, especially to analyse a wider number of samples for inclusion into the USDA isoflavone database.

Table 3. Flavonoid content of tree nuts indexed in the 2007 US Department of Agriculture flavonoid database ${ }^{(8)}$

\begin{tabular}{lccccc}
\hline Tree nut & $\begin{array}{c}\text { Flavan-3-ols } \\
(\mathrm{mg} / 100 \mathrm{~g})\end{array}$ & $\begin{array}{c}\text { Flavanones } \\
(\mathrm{mg} / 100 \mathrm{~g})\end{array}$ & $\begin{array}{c}\text { Flavonols } \\
(\mathrm{mg} / 100 \mathrm{~g}\end{array}$ & $\begin{array}{c}\text { Anthocyanins } \\
(\mathrm{mg} / 100 \mathrm{~g})\end{array}$ & $\begin{array}{c}\text { Flavonoids } \\
(\mathrm{sum})(\mathrm{mg} / 100 \mathrm{~g})\end{array}$ \\
\hline Almonds & 4.47 & 0.38 & 7.93 & 2.46 & 15.25 \\
Brazil nuts & 0.00 & 0.00 & 0.00 & 0.00 & 0.00 \\
Cashews & 1.98 & 0.00 & 0.00 & 0.00 & 1.99 \\
Hazelnuts & 5.25 & 0.00 & 0.00 & 6.71 & 11.99 \\
Macadamias & 0.00 & 0.00 & 0.00 & 0.00 & 0.00 \\
Pecans & 15.99 & 0.00 & 0.00 & 18.02 & 34.01 \\
Pine nuts & 0.49 & 0.00 & 0.00 & 0.00 & 0.49 \\
Pistachios & 6.85 & 0.00 & 1.46 & 6.06 & 18.00 \\
Walnuts, English & 0.00 & 0.00 & 0.00 & 2.71 & 2.74 \\
\hline
\end{tabular}


Table 4. Isoflavone content of tree nuts listed in the US Department of Agriculture database ${ }^{(7)}$

\begin{tabular}{lc}
\hline Tree nut & $\begin{array}{c}\text { Total isoflavones } \\
(\mathrm{mg} / 100 \mathrm{mg})\end{array}$ \\
\hline Almonds & 0.01 \\
Brazil nuts & 0.00 \\
Cashews & 0.01 \\
Hazelnuts & 0.03 \\
Macadamias & $\mathrm{NR}$ \\
Pecans & 0.00 \\
Pine nuts & $\mathrm{NR}$ \\
Pistachios & 3.63 \\
Walnuts, English & 0.03 \\
\hline
\end{tabular}

NR, not reported.

US Department of Agriculture phytochemical databases: proanthocyanidins. The USDA PAC database was released in $2004^{(9)}$. All of the tree nuts are included in the database, and values are based solely on the work by Gu et al. ${ }^{(1)}$. In this study, Brazil nuts, pine nuts and macadamias had no detectable PAC. Between five and eight samples were analysed for each tree nut, and each nut was assigned a confidence code of ' $\mathrm{A}$ '.

The USDA PAC database does not distinguish between A- and B-linked PAC or the polymer units (for example, catechin, epicatechin) and reports content as catechin equivalents. Therefore, the database is an approximation of PAC content. In part, this is due to lack of available standards for quantification and characterisation purposes. Also, since monomers are included, catechin and epicatechin content may overlap with the USDA flavonoid database flavan-3-ol content.

The majority of tree nut PAC are highly polymerised ( $>$ 10-mers). However, cashews only have monomer and dimer PAC. PAC are the predominant polyphenols in almonds, hazelnuts, groundnuts, pecans and pistachios. Hazelnuts and pecans have the highest PAC content with 501 and $494 \mathrm{mg} / 100 \mathrm{~g}$, respectively (Table 5). No PAC have been reported in Brazil nuts, macadamias or pine nuts, but Venkatachalam \& Sathe ${ }^{(13)}$ reported $10 \mathrm{mg}$ catechin equivalents $/ 100 \mathrm{~g}$ using a non-specific method of analysis.

Future revisions of the USDA PAC database may include information about subunits, linkages, and more information about their characterisation. Prodanov et al. ${ }^{(14)}$ and Monagas et al. ${ }^{(15)}$ provided qualitative and some quantitative information about almond and hazelnut PAC, but more work is needed to characterise PAC in these and other tree nuts, including developing quantitative methods.

Phenol-Explorer. Phenol-Explorer (PE) is a web-based database of the polyphenol content of foods ${ }^{(16)}$. PE was developed by Augustin Scalbert and colleagues at INRA Clermont-Ferrand, Unité de Nutrition Humaine. PE's webbased interface allows queries for foods or polyphenols. PE has more phenolic classes than the USDA databases, including 'total phenols', flavonoids, lignans, stilbenes, phenolic acids and other phenolics (Table 6).
Phenol-Explorer total phenol database. The PE database includes the total phenol value of each tree nut (Table 2). As compared with the USDA total phenol database derived from Wu et al. ${ }^{(5)}$, total phenol values presented in this database are derived from studies of Wu et $a l .{ }^{(5)}$ and Kornsteiner et al. ${ }^{(17)}$. Thus, the data retrieved in the PE database could be more consequential than those in the USDA database. Though not considered in detail in the present review, we note that chestnuts are included in the USDA total phenol database and are identified as having the highest total phenol content, followed by pecans, pistachios and walnuts.

Phenol-Explorer phytochemical database. PE is more versatile than the USDA phytochemical databases as it allows for conversion between units such as aglycone equivalents (the USDA database preferred method) or $\mathrm{mg} / 100 \mathrm{~g}$ or $\mathrm{mol} / 100 \mathrm{~g}$ equivalents for polyphenol glycosides. The web portal has an option for displaying polyphenol class totals. The polyphenol results are organised by method of quantification, such as chromatography, chromatography after hydrolysis, Folin assay (the common measure of total phenols), $\mathrm{pH}$ differential method for anthocyanin content, and normal-phase chromatography.

PE also has a variety of summary reports. The selected reports include alcoholic beverages, cereals, cocoa, fruits and fruit products, non-alcoholic beverages, oils, seasonings, seeds, soya and soya products, and vegetables. While tree nut oils are not included in the 'oils' report, tree nuts are included in the 'seeds' report.

We list the PE entries used for almonds, cashews, hazelnuts, pecans, pistachios and walnuts (Table 7). Notably, no flavonoid, PAC, or phenolic acid entries exist for Brazil nuts, macadamias or pine nuts. While Brazil nuts and macadamias have total phenol entries, pine nuts are not listed in PE. The flavonoid and PAC data included in PE for most tree nuts are largely similar to those in USDA databases. Accordingly, the data are mainly based on the references from Harnly et al. ${ }^{(10)}$ and $\mathrm{Gu}$ et $a l^{(1)}$ for flavonoid and PAC content. While groundnut isoflavones are listed in $\mathrm{PE}$, tree nut isoflavone content is not. Also, while lignans are included in PE, the studies by Thompson et al. ${ }^{(18)}$, Smeds et $a l^{(19)}$ and Kuhnle et $a l^{(12)}$ which quantified

Table 5. Total proanthocyanidins (PAC) content of tree nuts reported in the US Department of Agriculture database ${ }^{(9)}$

\begin{tabular}{lc} 
Tree nut & $\begin{array}{c}\text { Total PAC } \\
(\mathrm{mg} / 100 \mathrm{~g})\end{array}$ \\
\hline Almonds & 184.02 \\
Brazil nuts, dried, unblanched & 0 \\
Cashews, raw & 8.68 \\
Hazelnuts or filberts & 500.66 \\
Macadamia nuts, dry roasted, without salt added & 0 \\
Pecans & 494.05 \\
Pine nuts, pignolia, dried & 0 \\
Pistachios, raw & 237.34 \\
Walnuts, English & 67.25 \\
\hline
\end{tabular}


Table 6. Polyphenols included in the Phenol-Explorer database ${ }^{(16)}$

\begin{tabular}{ll}
\hline Polyphenol class & Subclass \\
\hline Flavonoids & Anthocyanins \\
& Chalcones \\
& Dihydrochalcones \\
& Dihydroflavonols \\
& Flavonols \\
& Flavanones \\
& Flavones \\
& Flavonols \\
& Isoflavonoids \\
Lignans & Lignans \\
Other polyphenols & Alkylmethoxyphenols \\
& Alkylphenols \\
& Curcuminoids \\
& Furanocoumarins \\
& Hydroxybenzaldehydes \\
& Hydroxybenzoketones \\
& Hydroxycinnamaldehydes \\
& Hydroxycoumarins \\
& Hydroxyphenylpropenes \\
& Methoxyphenols \\
& Naphthoquinones \\
& Phenolic terpenes \\
Tyrosols \\
Phenolic acids & Other polyphenols \\
& Hydroxybenzoic acids \\
& Hydroxycinnamic acids \\
& Hydroxyphenylacetic acids \\
& Hydroxyphenylpropanoic acids \\
& Stilbenes \\
\hline & \\
& \\
& \\
&
\end{tabular}

lignans in many of the tree nuts are not currently entered. Therefore, existing and future studies of tree nut phytochemicals should be submitted to PE for inclusion. The PAC content of tree nuts is also listed in PE, and appears less than the values for the USDA PAC database (Table 8). This is because PE does not include PAC monomers in foods from Gu et al. ${ }^{(1)}$.

PE includes data for phenolic acids, stilbenes and naphthoquinones, which are not currently accounted for in the USDA phytochemical databases. Since PE has the ability to compile data for more polyphenol classes, is updated more frequently than USDA databases, and contains a greater number of food types, PE may become more widely used among polyphenol researchers than USDA databases. Nevertheless, existing quality data regarding tree nut lignans, flavonoids, alkylphenols and isoflavones should be submitted to PE for consideration of inclusion in the database.

The PE database has been recently employed to identify the richest dietary sources of polyphenols (as the sum of the contents of all individual polyphenols) and their intake among a large cohort of adults. Pérez-Jiménez et $a l{ }^{(20)}$ reported five tree nuts (chestnuts, hazelnuts, pecans, almonds and walnuts) among the richest 100 dietary sources of polyphenols at a rank of 11, 21, 22, 40 and 79 containing 1215, 495, 493, 187 and $28 \mathrm{mg} / 100 \mathrm{~g}$, respectively. Based upon serving sizes of 19, 28, 15 and $10 \mathrm{~g}$, chestnuts, hazelnuts, pecans and almonds were ranked as
$15,21,33$ and 62 for their total polyphenol content of 230, 138, 69 and $19 \mathrm{mg} /$ serving. It is noteworthy that using PE, the values obtained using the Folin assay were found to systematically exceed the total polyphenol content values. Using the French cohort of the SUpplémentation en VItamines et Minéraux AntioXydants (SU.VI.MAX) trial, Pérez-Jiménez et al. ${ }^{(21)}$ assessed the dietary polyphenol intake of 4942 men and women aged 45-60 years and found total polyphenol intakes at 1193 (SD 510) $\mathrm{mg} / \mathrm{d}$ per person with 8 (SD 18) $\mathrm{mg} / \mathrm{d}$ derived from seeds, with 37 , 27 and 14\% of this amount from walnuts, hazelnuts and chestnuts, respectively. Further, of the 41 (SD 39) $\mathrm{mg} / \mathrm{d}$ per person intake of hydroxybenzoic acids, $8 \%$ was derived from walnuts; of the 12 (SD 22) $\mathrm{mg} / \mathrm{d}$ per person (-)-epigallocatechin intake, 99\% was derived from tea but $0.2 \%$ was consumed as almonds. In contrast, calculating total dietary polyphenols as the sum of extractable polyphenols, condensed tannins and hydrolysable polyphenols determined in their laboratory, Saura-Calixto et $a{ }^{(22)}$ reported a total bioaccessible polyphenol intake of $2533 \mathrm{mg} / \mathrm{d}$ per person in Spain, with $107 \mathrm{mg} / \mathrm{d}$ per person derived from consumption of a mean of $5.9 \mathrm{~g}$ nuts/d.

US Department of Agriculture National Nutrient Database for Standard Reference for sterols. Phytosterols of tree nuts are reported in the USDA National Nutrient Database for Standard Reference, release 23 (SR-23) ${ }^{(23)}$. The $\beta$-sitosterol campesterol and stigmasterol contents of most tree nuts are reported, excluding Brazil nuts and cashews (Table 9). Unlike the USDA phytochemical database, the tree nut phytosterol data in SR-23 are not derived from literature reports, but rather from data supplied by tree nut commodity boards and the Hammons Products Company in the case of black walnuts.

The SR-23 phytosterol data for tree nuts range from $72 \mathrm{mg} / 100 \mathrm{~g}$ in English walnuts to $214 \mathrm{mg} / 100 \mathrm{~g}$ in

Table 7. Phenol-Explorer concentration of flavonoids, phenolics, stilbenes and other phenols in nuts ${ }^{(16)}$

\begin{tabular}{|c|c|c|}
\hline Tree nut & $\begin{array}{l}\text { Concentration } \\
(\mathrm{mg} / 100 \mathrm{~g} \mathrm{fw})\end{array}$ & $\begin{array}{l}\text { Polyphenol classes, in } \\
\text { order of abundance }\end{array}$ \\
\hline Almonds & $8 \cdot 90$ & $\begin{array}{l}\text { Flavonols, flavanols, } \\
\text { flavanones, } \\
\text { hydroxybenzoic acids }\end{array}$ \\
\hline Cashew nuts & $1 \cdot 10$ & Flavanols \\
\hline Hazelnuts & $5 \cdot 70$ & Flavanols \\
\hline Japanese walnuts & $15 \cdot 7$ & Hydroxybenzoic acids \\
\hline Pecan nuts & $16 \cdot 7$ & Flavanols \\
\hline Pistachios & 6.90 & Flavanols \\
\hline Pistachios, dehulled & 0.406 & $\begin{array}{l}\text { Stilbenes, flavanones, } \\
\text { flavonols, flavones }\end{array}$ \\
\hline Walnuts & 28.5 & Hydroxybenzoic acids \\
\hline Walnuts, dehulled & 54.6 & $\begin{array}{l}\text { Hydroxybenzoic acids, } \\
\text { naphthoquinones, } \\
\text { hydroxycinnamic acids, } \\
\text { hydroxybenzoic acids, } \\
\text { hydroxybenzaldehydes }\end{array}$ \\
\hline
\end{tabular}

fw, Fresh weight. 
Table 8. Phenol-Explorer listed concentration of nut proanthocyanidins ${ }^{(16)}$

\begin{tabular}{|c|c|c|}
\hline Tree nut & $\begin{array}{l}\text { Concentration } \\
(\mathrm{mg} / 100 \mathrm{~g} \mathrm{fw})\end{array}$ & Polymerisation, in order of abundance \\
\hline Almonds & $176 \cdot 3$ & Polymers (>10-mers), 4-6-mers, 7-10-mers, dimers, trimers \\
\hline Cashew nuts & 2.0 & Dimers \\
\hline Hazelnuts & $490 \cdot 8$ & Polymers (>10-mers), 7-10-mers, 4-6-mers, trimers, dimmers \\
\hline Pecan nuts & 476.7 & Polymers ( $>10$-mers), 4-6-mers, $7-10$-mers, dimers, trimers \\
\hline Pistachios & $226 \cdot 4$ & Polymers (>10-mers), 4-6-mers, 7-10-mers, dimers, trimers \\
\hline Walnuts & $60 \cdot 3$ & 4-6-mers, polymers ( $>10$-mers), trimers, dimers, $7-10$-mers \\
\hline
\end{tabular}

fw, Fresh weight.

pistachios. Tree nuts are mainly composed of $\beta$-sitosterol, but are also composed of a number of minor sterols, sterol esters and stanols. Thus, the phytosterol values for most tree nuts in SR-23 are somewhat less than literature values due to the contribution of other minor sterols.

The SR-23 data could be immediately improved by submitting data for Brazil nuts and cashews that contain 154 to $190 \mathrm{mg}$ sterols/100 g. The USDA Nutrient Data Laboratory encourages submission of data to support SR-23, so the phytosterol data could potentially be updated. Since the almond data for total sterol content include minor sterols, it is plausible that these data could be included for other tree nuts and would more accurately reflect tree nut sterol content.

US Department of Agriculture National Nutrient Database for Standard Reference for carotenoids. The USDA SR-23 database also includes vitamin A equivalents, $\beta$-carotene, $\alpha$-carotene, $\beta$-cryptoxanthin, lycopene, lutein and zeaxanthin content of tree nuts. As previously reported, raw pistachios have the highest carotenoid content among tree nuts, which is reported mainly as $1205 \mu \mathrm{g}$ lutein and zeaxanthin $/ 100 \mathrm{~g}$ pistachios, resulting in $415 \mathrm{IU}$ vitamin A/100g. Raw and dry roasted pistachios also have 13 and 21 retinoic acid equivalents/100 g. Similar to the data on phytosterols, some SR-23 tree nut carotenoid entries are derived from data submitted by tree nut commodity boards, but also include data generated by the USDA Nutrient Data Laboratory and a study by Perry et $a l .{ }^{(24)}$. As most tree nuts are not significant dietary sources of carotenoids, an effort to improve carotenoid data may not be worthwhile.

European Food Information Resource database. EuroFIR is funded through the European Union to develop a comprehensive food databank to be used as a single authoritative source for European food composition data $^{(25)}$. Additionally, EuroFIR has published reports about food and health, including a statement about nuts and risk of CVD. EuroFIR is developing a database for bioactive foods components. This database is unique in that it will compile both content and bioactivity data. The EuroFIR database, eBASIS (BioActive Substances in Food Information System), is not yet publicly available, but is currently available to member institutions.

Table 9. Phytosterol content of tree nuts, according to US Department of Agriculture 2009 National Nutrient Database for Standard Reference, release $23^{(23)}$

\begin{tabular}{|c|c|c|c|c|c|}
\hline \multirow[b]{2}{*}{ Tree nut } & \multirow[b]{2}{*}{ Type } & \multicolumn{4}{|c|}{ Sterol content $(\mathrm{mg} / 100 \mathrm{~g})$} \\
\hline & & $\beta$-Sitosterol & Campesterol & Stigmasterol & Sum \\
\hline \multirow[t]{4}{*}{ Almonds } & Raw $^{*}$ & 132 & 5 & 4 & 172 \\
\hline & Blanched & 109 & 6 & 1 & 116 \\
\hline & Dry roasted & 110 & 3 & 4 & 118 \\
\hline & Oil roasted & 118 & 9 & 3 & 130 \\
\hline Brazil nuts & & NR & NR & NR & NR \\
\hline Cashews & & NR & NR & NR & NR \\
\hline \multirow[t]{3}{*}{ Hazelnuts } & Raw & 89 & 6 & 1 & 96 \\
\hline & Blanched & 108 & 7 & 1 & 116 \\
\hline & Dry roasted & 103 & 6 & 1 & 110 \\
\hline \multirow[t]{2}{*}{ Macadamias } & Raw & 108 & 8 & 0 & 116 \\
\hline & Dry roasted & 107 & 7 & 0 & 114 \\
\hline \multirow[t]{3}{*}{ Pecans } & Raw & 89 & 5 & 3 & 102 \\
\hline & Dry roasted & 78 & 4 & 2 & 85 \\
\hline & Oil roasted & 96 & 7 & 5 & 108 \\
\hline Pine nuts & Dried & 141 & NR & NR & NR \\
\hline \multirow[t]{2}{*}{ Pistachios } & Raw & 198 & 10 & 5 & 214 \\
\hline & Dry roasted & 200 & 10 & 4 & 214 \\
\hline \multirow{2}{*}{ Walnuts } & Black & 103 & 5 & 0 & 108 \\
\hline & English & 64 & 7 & 1 & 72 \\
\hline
\end{tabular}

NR, not reported.

* Other, $\delta$-5-avenasterol, sitostanol, campestanol and other minor phytosterols. 


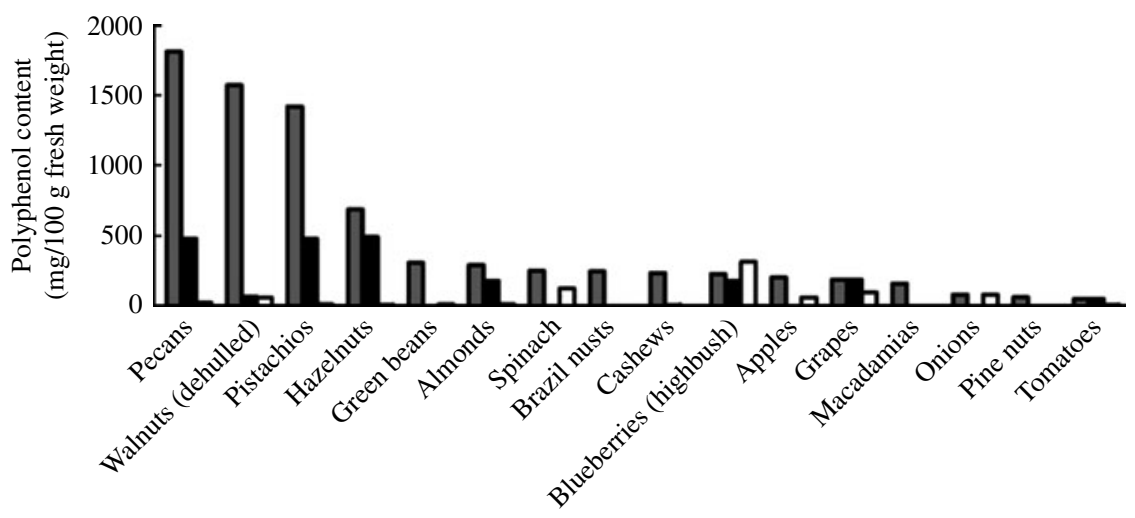

Fig. 3. Polyphenol content of reference foods and tree nuts in the Phenol-Explorer database. ( $\square$ ), Total phenols; ( $\square$ ), polyphenols by HPLC; proanthocyanidins.

Comparison of tree nut phytochemical database values relative to other foods. A report by Pérez-Jiménez et $a l^{(20)}$ used the $\mathrm{PE}$ database to compare the richest sources of dietary polyphenols. The seeds category, which includes tree nuts, was ranked third behind spices and fruits for containing the most number of items in their list of the 100 foods with the highest polyphenol content. Walnuts, hazelnuts and chestnuts were identified as main contributors to polyphenol content within the seeds class.

To compare tree nut phytochemical content with other whole plant foods, we retrieved database values for fruits and vegetables from PE. Apples, highbush blueberries, purple grapes, green beans, spinach, tomatoes and yellow onions were selected because they are commonly consumed and available for consumption in the USA. Polyphenol values were retrieved from PE and carotenoid and phytosterol values were from the USDA SR-23 database.

The reference fruits and vegetables had phytosterol values of 4 to $15 \mathrm{mg} / 100 \mathrm{~g}$, while tree nuts had 72 to $214 \mathrm{mg} / 100 \mathrm{~g}$. Spinach, tomatoes and green beans carotenoid and xanthophyll content provide 690 to 9377 IU vitamin A, which is significantly greater than for tree nuts. Pecans, walnuts, pistachios and hazelnuts had more than double total phenols and PAC than the comparison foods (Fig. 3). Almond, Brazil nut and cashew total phenols were comparable with those of green beans, spinach, blueberries and apples. The PAC content of almonds was similar to those of grapes and blueberries. Polyphenol content by HPLC varied, with blueberries, grapes, spinach and apples having 56 to $310 \mathrm{mg} / 100 \mathrm{~g}$, while tree nuts had $1 \cdot 1$ to $54 \mathrm{mg} / 100 \mathrm{~g}$. The stilbene content of purple grapes was comparable with that of pistachios, with 0.19 and $0 \cdot 11 \mathrm{mg} / 100 \mathrm{~g}$, respectively. The database value for pistachio content is somewhat higher than the literature average of $0.8 \mathrm{mg}$ stilbene $/ 100 \mathrm{~g}$ (Table 10). Walnuts and walnut liquor were the only foods with naphthoquinone content in PE. Alkylphenol contents of cashews and pistachios are not reported in $\mathrm{PE}$, or for the reference vegetables. However, bran breakfast cereals and whole grain flour bread have 286 and $25 \mathrm{mg} / 100 \mathrm{~g}$, respectively. Several reports in the literature have assigned 144 and $44 \mathrm{mg}$ alkylphenols/100 g for cashews and pistachios, respectively (Table 11). Similarly, while tomatoes have $0.02 \mathrm{mg}$ lignan $/ 100 \mathrm{~g}$, tree nuts values which range from 0.02 to $0.97 \mathrm{mg}$ lignin $/ 100 \mathrm{~g}$ are not reported in PE (Table 11). Since all of the polyphenol classes have not been comprehensively surveyed in fruits, vegetables and tree nuts, it is difficult to draw reliable conclusions about the polyphenol abundance from HPLC analysis alone. More work is necessary to characterise, quantify and report fruit, vegetable and tree nut polyphenol values to phytochemical databases.

Tree nut phytochemical values reported after database publication

We conducted a comprehensive search of the Chemical Abstracts (CAPLUS) and MedLine literature databases to obtain the most recent qualitative and quantitative information on tree nut phytochemicals in January and February 2010 and updated our search in May 2011. From the initial search, we retrieved 368 references pertaining to the phytochemical composition of tree nuts. Then we extracted information including the source and type of tree nut and extraction and analytical methods. In some cases, the data needed to be transformed into values reflecting the content on a $100 \mathrm{~g}$ fresh weight of tree nut basis. These results are summarised in Table 10, Table 11 and Fig. 4, and elaborated on below.

\section{Total phenols and flavonoids}

Total phenols. The total phenol values among the nine tree nuts reviewed here vary widely (Table 10), with walnuts and pecans being the top two, followed by pistachios with its value being $50 \%$ lower. Almonds, Brazil nuts, cashews, macadamias and pine nuts all contain similar total phenol content between 200-300 mg GAE/100 g. 


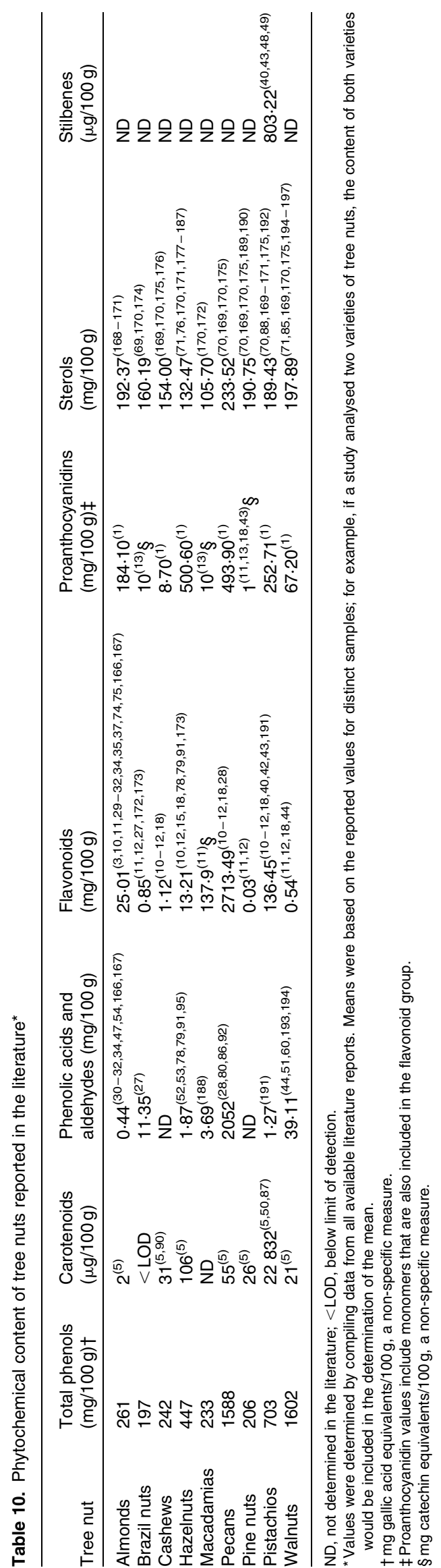

As compared with the data presented in the two databases (USDA and PE), total phenol values of almonds, Brazil nuts, cashews, macadamias, pecans and walnuts are not markedly different while mean literature values of hazel nuts and pistachios are 50\% lower than database values and pine nuts are 2 -fold larger. There are numerous factors that contribute to the inconsistency in the reported values, including the specific methodology for extraction of the phenols, nut cultivars and nut processing. This issue is discussed below.

Flavonoids. Literature values for flavonoid content of tree nuts range from $0.03 \mathrm{mg} / 100 \mathrm{~g}$ in pine nuts to $2700 \mathrm{mg} / 100 \mathrm{~g}$ in pecans (Table 10). The content of flavonoids has been reported for each tree nut, but comprehensive and systematic investigations characterising flavonoids from tree nuts are lacking. For example, Brazil nuts are reported to have $108 \mathrm{mg}$ flavonoids $/ 100 \mathrm{~g}$ by Yang et al. ${ }^{(11,26)}$ using a non-specific measure of flavonoids. In contrast, Harnly et al. ${ }^{(10)}$ did not find flavonoids in Brazil nuts ${ }^{(10)}$. Brazil nuts contain the isoflavones daidzein and biochanin A, albeit at low levels ${ }^{(12)}$. John \& Shahidi ${ }^{(27)}$ quantified catechin, ellagic acid and phenolic acids in Brazil nuts, but about 10-fold less than the report by Yang et al. ${ }^{(11)}$. Similarly, Yang et al. found $137.9 \mathrm{mg}$ catechin equivalents/100 $\mathrm{g}$ in macadamias ${ }^{(11)}$. Thus, a more careful and comprehensive analysis of macadamia and Brazil nut flavonoids and phenolics is warranted.

Flavonoids: pecans. Pecans have an apparently high value for flavonoid content because Malik et al. ${ }^{(28)}$ reported 1800 to $4700 \mathrm{mg}$ catechin/100 g pecans. This is significantly larger than the report by Harnly et $a l^{(10)}$ of only $7.2 \mathrm{mg}$ catechin/100g pecans. The reason(s) for this extreme difference is not clear, as both techniques employed direct extraction and used similar methods for quantification. Potentially important, Malik et al. ${ }^{(28)}$ used defatted kernels for extraction, whereas Harnly et al. ${ }^{(10)}$ did not.

Flavonoids: almonds. For almonds, a number of reports were published after the USDA flavonoid database release. These include studies from Monagas et al. ${ }^{(3)}$, Hughey et al. ${ }^{(29)}$, Garrido et $a l .{ }^{(30)}$, Mandalari et $a l .{ }^{(31)}$, Bolling et $a l^{(32,33)}$ and Teets et $a l^{(34)}$. However, earlier reports by Chen et al. ${ }^{(35)}$ and Frison et al. ${ }^{(36,37)}$ were not included in the last revision of the USDA flavonoid database. Combining these reports yields an average of $25.01 \mathrm{mg}$ flavonoids/100 $\mathrm{g}$ almonds.

Flavonoids: cashews. A systematic investigation into cashew flavonoid content is lacking, but Kuhnle et al. ${ }^{(12)}$ added to the values of formononetin and biochanin $\mathrm{A}$ reported in the USDA isoflavone database and PE.

Flavonoids: hazelnuts. Polyphenols have been further characterised in hazelnut skins. Monagas et al. ${ }^{(15)}$ reported the catechin content and Del Rio et al. ${ }^{(38)}$ reported monomeric and oligomeric flavan-3-ols, flavonols, dihydrochalcones and phenolic acids in hazelnut skins. Although these studies did not report polyphenol content in terms of whole hazelnuts, monomeric and oligomeric 
flavan-3-ols were found to be the predominant polyphenol subclass, accounting for $95 \%$ of total polyphenols ${ }^{(38)}$. In other studies, Yurttas et $a l .{ }^{(39)}$ reported quercetin from hazelnut extracts, whereas Harnly et al. ${ }^{(10)}$ did not detect quercetin following acid hydrolysis of extracts.

Flavonoids: pistachios. In their analysis of pistachios, Ballistreri et al. ${ }^{(40)}$ and Seeram et al. ${ }^{(41,42)}$ found eriodictyol and anthocyanin. Gentile et $a l .{ }^{(43)}$, Seeram et al. ${ }^{(42)}$ and Kuhnle et $a l^{(12)}$ also reported new isoflavone data for pistachios that could be included in future USDA database updates.

Flavonoids: walnuts. Catechin was detected in extracts of walnuts by Gómez-Caravaca et al. ${ }^{(44)}$. Quercetin was found in black walnuts but not quantified by Anderson et $a l^{(45)}$. Kuhnle et $a l .{ }^{(12)}$ added to the isoflavone data available for walnuts.

The widespread presence of flavonoids in tree nuts but the absence of data on the flavonoid content of macadamias, Brazil nuts and pine nuts suggests that thoughtful analyses of these nuts are warranted. Importantly, since truly comprehensive analyses of flavonoids in most tree nuts are lacking and further work to optimise extraction methods is required, further studies are required to confirm and extend the accuracy, breadth and reliability of the available quantitative data.

\section{Proanthocyanidins}

A number of non-specific measures of PAC content exist for all tree nuts. However, only studies of almond PAC by Amarowicz et al. ${ }^{(46)}$, Prodonov et al. ${ }^{(14)}$ and Urpi-Sarda et $a l .{ }^{(47)}$ and a study of PAC in almond and hazelnut skins by Monagas et al. $^{(15)}$ have added qualitative and quantitative data on tree nut PAC since the report by Gu et $a l .{ }^{(1)}$. Since PAC are estimated to be the most abundant polyphenols in tree nuts, more efforts are needed to develop quantitative methods of PAC analysis in tree nuts.

\section{Stilbenes}

Pistachios are the only tree nut with reported stilbene content, with $803 \mu \mathrm{g} / 100 \mathrm{~g}$. Only the study by Tokusoglu et $a l .{ }^{(48)}$ is included in PE. Studies by Gentile et al. ${ }^{(43)}$, Grippi et al. ${ }^{(49)}$ and Ballistreri et al. ${ }^{(40)}$ have reported on the stilbene content of pistachios but these data have yet to be submitted or included in the PE database. Other tree nuts may contain stilbenes, but a systematic analysis of their abundance is lacking.

\section{Phytosterols}

More than sixty studies have reported tree nut sterol data, but only one is included in the SR-23 database. Notably, cashews and Brazil nuts have significant phytosterol content, but are not included in the SR-23 database. Nearly all values are reported on an oil basis, so future research 
efforts should also report values on a whole-nut basis to facilitate entry into databases. Preliminary reports suggest eBASIS also contains values for tree nut sterols. Minor sterols, sterol esters and stanols have been quantified in tree nuts or their oils (Table 12).

\section{Carotenoids}

In addition to the USDA SR-23 database, Kornsteiner et $a l .{ }^{(5)}$ reported lutein and $\beta$-carotene in tree nuts.

(c)
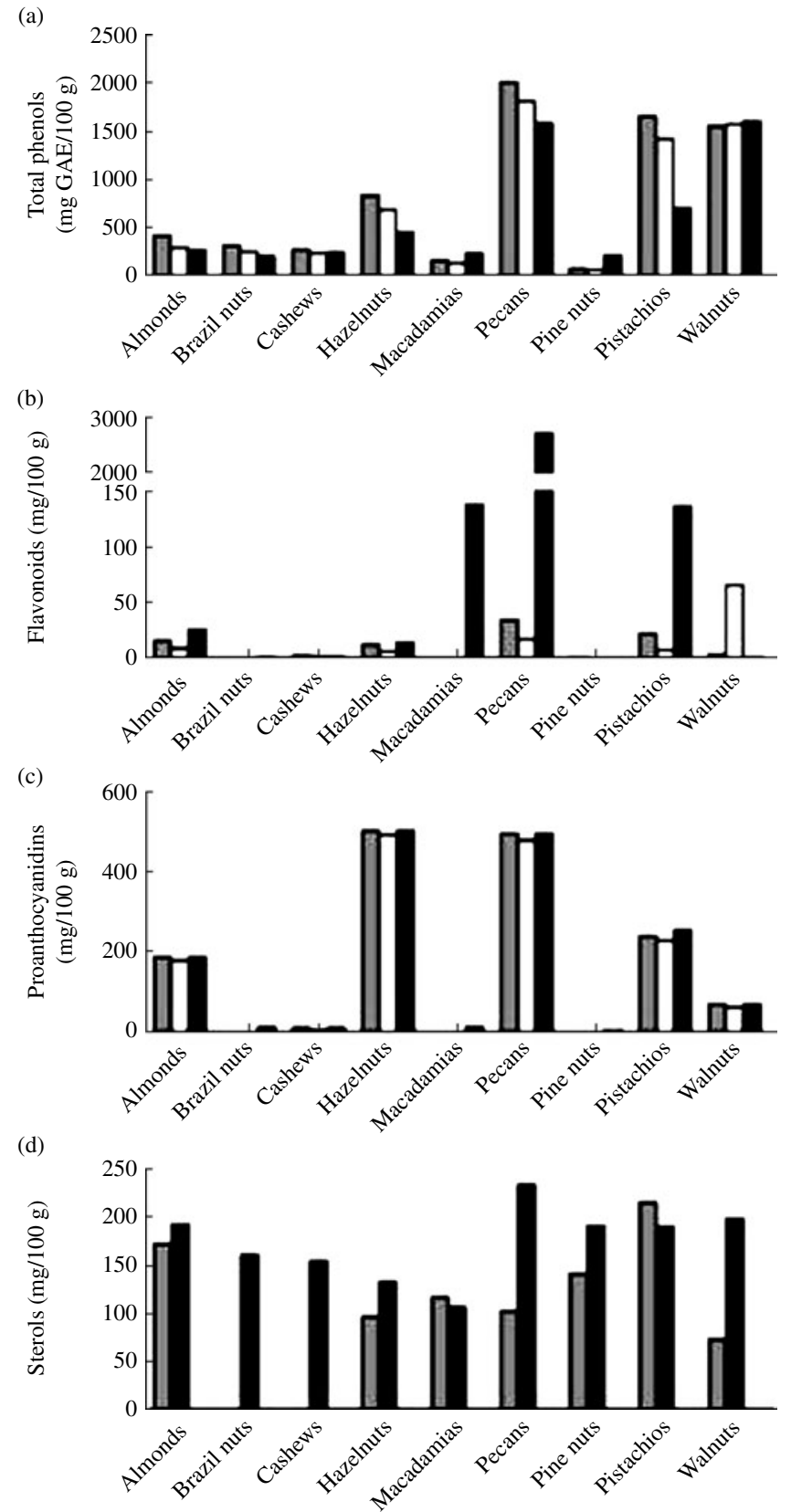

Fig. 4. Phytochemical database values for tree nuts relative to current literature (ם) values for (a) total phenols, (b) flavonoids, (c) proanthocyanidins and (d) sterols. ( $\square$ ), US Department of Agriculture; ( $\square$ ), Phenol-Explorer; GAE, gallic acid equivalents.
Bellomo et $a l .{ }^{(50)}$ further reported on the lutein content of pistachios.

\section{Other classes}

Phenolic acids and aldehydes. PE includes values for simple phenolics in tree nuts. Pecans and walnuts have high simple phenolic content at 2558 and $39 \cdot 1 \mathrm{mg} / 100 \mathrm{~g}$, respectively. The phenolic acids of pecans are primarily gallic acid, while those of walnuts are syringic acid. A high content of ellagic acid $(28.5 \mathrm{mg} / 100 \mathrm{~g})$ was found in Persian walnuts by $\mathrm{Li}$ et $a{ }^{(51)}$. Gómez-Caravaca et $a .^{(44)}$, Shahidi et $a l^{(52)}$ and Alasalvar et al. ${ }^{(53)}$ also reported quantitative data for phenols in walnuts and hazelnuts, but these data have not been entered into PE. Wijeratne et al. ${ }^{(54,55)}$ reported simple phenolics in almond skin, but the quantitative data are not reported on a nut basis. More recently, Mandalari et al. ${ }^{(31)}$ have reported on a variety of phenolic acids in almond skin; these data are not included in the current version of PE.

No quantitative data for simple phenols are reported for cashews or pine nuts. Thus, a systematic evaluation of phenols in these tree nuts would be useful to establish the simple phenols present in these nuts.

Alkaloids. One report by Reiter et al. ${ }^{(56)}$ quantified melatonin in walnuts. There are no other qualitative reports of phyto-alkaloids in tree nuts.

Phytates. Tree nuts contain a significant amount of phytates, from 100 to $2500 \mathrm{mg} / 100 \mathrm{~g}$ (Table 11). Almonds have the highest reported phytate content, with pine nuts and Brazil nuts having the lowest content.

Chlorophylls. Pistachios have the highest chlorophyll content at $11000 \mu \mathrm{g} / 100 \mathrm{~g}$. In contrast, pine nuts (Aleppo pine nuts; Pinus halepensis Mill.) harvested in Tunisia contain $3 \mu \mathrm{g} / 100 \mathrm{~g}$ chlorophyll. No other published information is available on the chlorophyll content of other tree nuts.

Lignans. Lignans are included in the PE and eBASIS databases. Tree nuts contain 67-973 $\mu \mathrm{g}$ lignans/100 g, with the highest values reported for cashews (Table 11). To date, there have been no reports of lignans in macadamia nuts. Smeds et al. ${ }^{(19)}$, Thompson et al. ${ }^{(18)}$ and Kuhnle et $a l .{ }^{(12)}$ each reported tree nut lignans. Future studies should also investigate the lignan content of macadamias.

Alkylphenols. Cashews and pistachios have significant alkylphenol contents at 144 and $44 \mathrm{mg} / 100 \mathrm{~g}$, respectively. The alkylphenols in cashews and other tree nuts are principally cardanols, anacardic acid and cardols ${ }^{(57-59)}$.

Naphthoquinones. Pecans and walnuts have 41 and $12 \mathrm{mg}$ juglone/100 g, respectively. Naphthoquinones have not been reported in other tree nuts. Data from Colaric et $a l .{ }^{(60)}$ for walnut juglone are included in $\mathrm{PE}$. The pecan juglone content reported by Hedin et al. ${ }^{(61)}$ (regarding tree leaves) and Borazjani et al. ${ }^{(62)}$ used less reliable methods for their analyses and, thus, are unlikely to be included in the PE database. Thus, an updated survey of juglone in pecan kernels is necessary to include this nut in PE. 
Table 12. Sterols, stanols and sterol esters quantified in tree nuts

\begin{tabular}{|c|c|}
\hline Sterols, stanols or sterol esters & Tree nut \\
\hline 22-Nordehydrocholesterol & Brazil nuts, pine nuts, pistachios \\
\hline 24-Ethylcholest-4-ene-6 $\alpha$-ol-3-one & Hazelnuts \\
\hline 24-Hydroxycampesterol & Hazelnuts \\
\hline 24-Methylcholesterol & Pine nuts \\
\hline 24-Methylenecholesterol & Brazil nuts, pecans, walnuts \\
\hline 24-Methylenecycloartanol & Almonds, cashews, pistachios, walnuts, hazelnuts \\
\hline 25-Hydroxysitosterol & Hazelnuts \\
\hline 31-Norcycloartenol & Cashews, pecans, pine nuts \\
\hline 31-Norlanosterol & Pecans, walnuts \\
\hline $5 \alpha, 6 \alpha$-Epoxysitosterol & Hazelnuts \\
\hline $6 \beta$-Hydroxysitostanol & Hazelnuts \\
\hline 7-Ketocampesterol & Hazelnuts \\
\hline 7-Stigmastenol & Brazil nuts \\
\hline $7 \alpha$-Hydroxycampesterol & Hazelnuts \\
\hline $7 \beta$-Hydroxysitostanol & Hazelnuts \\
\hline Brassicasterol & Walnuts \\
\hline Butyrospermol & Hazelnuts \\
\hline Campestanetriol & Hazelnuts \\
\hline Campestanol & $\begin{array}{l}\text { Almonds, cashews, hazelnuts, macadamias, } \\
\text { pine nuts, pistachios, walnuts }\end{array}$ \\
\hline Chlerosterol & Hazelnuts \\
\hline Cholestanol & Brazil nuts, pine nuts \\
\hline Cholesterol & Almonds, cashews, pecans, pistachios, walnuts \\
\hline Citrostadienol & $\begin{array}{l}\text { Almonds, Brazil nuts, cashews, hazelnuts, pecans, } \\
\text { pine nuts, pistachios, walnuts }\end{array}$ \\
\hline Clerosterol & Hazelnuts, walnuts \\
\hline Cycloartanol & Almonds, cashews, pecans, pistachios, walnuts \\
\hline Cycloartenol & Brazil nuts, hazelnuts, pine nuts, pistachios, walnuts \\
\hline Cyclobranol & Pecans \\
\hline Cycloeucalenol & Cashews \\
\hline Cyclolaudenol & Cashews \\
\hline Cyclorbranol & Hazelnuts \\
\hline Fucosterol & Cashews \\
\hline Geranyl-geraniol & Hazelnuts \\
\hline Gramisterol & Almonds, hazelnuts, pecans, pine nuts, pistachios, walnuts \\
\hline Lanostenol & Pistachios \\
\hline Lophenol & Cashews \\
\hline Lupeol & Cashews, hazelnuts \\
\hline Obtusifoliol & Almonds, cashews, hazelnuts, pine nuts, pistachios, walnuts \\
\hline Phytol & Hazelnuts \\
\hline Sitostanetriol & Hazelnuts \\
\hline Sitostanol & Almonds, Brazil nuts, pine nuts, pistachios, walnuts \\
\hline Stigmastadienol & Hazelnuts \\
\hline Stigmastanol & Almonds, walnuts \\
\hline$\alpha$-Amyrin & Brazil nuts \\
\hline$\beta$-Amyrin & Brazil nuts, cashews, hazelnuts \\
\hline$\Delta 5,24$-Stigmastadienol & Hazelnuts, pine nuts, walnuts \\
\hline$\Delta 5$-Avenasterol & $\begin{array}{l}\text { Almonds, Brazil nuts, cashews, hazelnuts, macadamias, } \\
\text { pine nuts, walnuts }\end{array}$ \\
\hline$\Delta 5$-Stigmastadienol & Hazelnuts \\
\hline$\Delta 7$-Avenasterol & Almonds, hazelnuts, pine nuts, walnuts \\
\hline$\Delta 7$-Campesterol & Hazelnuts, pine nuts \\
\hline$\Delta 7$-Stigmastenol & Almonds, hazelnuts, pine nuts \\
\hline$\Delta$-Amyrin & Hazelnuts \\
\hline
\end{tabular}

Hydrolysable tannins. HT have only been quantified in walnuts, with $27.56 \mathrm{mg} / 100 \mathrm{~g}$. Glansreginins A and B are the only HT to be quantified, but more than fifty HT have been characterised in walnuts ${ }^{(45,63-68)}$. Future efforts should focus on quantifying these HT in walnuts. The presence of ellagic acid in pecans and almonds and gallic acid in pecans and hazelnuts also suggests that more work is needed to characterise HT in these nuts. Thus, efforts should be made to determine structures of HT in walnuts and other tree nuts.
Sphingolipids. Sphingolipids, mainly squalene and cerebroside, have been reported in all tree nuts except macadamias. Reported sphingolipid content ranges from $0.4 \mathrm{mg} / 100 \mathrm{~g}$ in pistachios to $612 \mathrm{mg} / 100 \mathrm{~g}$ in walnuts. Brazil nuts also have high sphingolipid content at $593 \mathrm{mg} / 100 \mathrm{~g}$. The majority of the sphingolipid data have been derived by Miraliakbari \& Shahidi ${ }^{(69-71)}$ utilising a non-specific method of quantification. Thus, more effort is needed to gain reliable data for the sphingolipid content of tree nuts. 


\section{Summary of phytochemical databases}

\section{Current knowledge}

Tree nuts contain an abundance of phytochemicals. All tree nuts contain significant amounts of phytates $(0.2$ to $2.5 \mathrm{~g} /$ $100 \mathrm{~g}$ ) and sterols (106 to $234 \mathrm{mg} / 100 \mathrm{~g}$ ). Relative to other tree nuts, almonds, hazelnuts, pecans and pistachios have higher contents of PAC, ranging from 184 to $501 \mathrm{mg} / 100 \mathrm{~g}$. Flavonoids have been detected in all tree nuts, but pecans, macadamias, almonds and pistachios have the highest concentrations ( 25 to $2713 \mathrm{mg} / 100 \mathrm{~g}$ ). Pecans and walnuts have appreciable phenolic acids and aldehydes, with 2052 and $39 \mathrm{mg} / 100 \mathrm{~g}$, respectively, but not all tree nuts have been surveyed for simple phenolics. Brazil nuts, almonds, pecans, pine nuts and walnuts have significant sphingolipid content, with 304 to $613 \mathrm{mg} / 100 \mathrm{~g}$. Cashews and pistachios have significant alkylphenol content, with 44 to $144 \mathrm{mg} / 100 \mathrm{~g}$. Pistachios have higher carotenoids and chlorophylls than other tree nuts, and also have been found to contain stilbenes at $803 \mu \mathrm{g} / 100 \mathrm{~g}$. Lignans have been quantified in all tree nuts except macadamias, and are present at 21 to $973 \mu \mathrm{g} / 100 \mathrm{~g}$. Walnuts and pecans contain naphthoquinones at 12 and $41 \mathrm{mg} / 100 \mathrm{~g}$, respectively, and walnuts have $28 \mathrm{mg} \mathrm{HT} / 100 \mathrm{~g}$ and trace amounts of the alkaloid melatonin. Phytochemical databases do not index all tree nut phytochemicals, but more recent databases such as PE and eBASIS are more comprehensive indexes of bioactives. Further, all databases do not include key studies of tree nut phytochemicals.

\section{Knowledge gaps}

The present review of the literature on tree nut phytochemicals and associated database values has identified several gaps in knowledge or inconsistencies about tree nut phytochemicals, including:

(a) Studies identified flavonoids in cashews, macadamias and Brazil nuts by non-specific methods. However, no studies have characterised flavonoids in these nuts sufficiently by reliable methods such that they cannot be included in phytochemical databases.

(b) Despite total phenol content, studies are not available that have characterised simple phenolic compounds in pine nuts. A robust characterisation of simple phenols in other tree nuts is also lacking.

(c) Except for almonds, no studies have quantified the common flavonoids isorhamnetin and kaempferol in tree nuts.

(d) Confidence codes for USDA isoflavone data of tree nuts are low to poor.

(e) Except for pistachios, no tree nuts have been surveyed for stilbenoids.

(f) Except for walnuts, HT have not been quantified in tree nuts despite evidence for their presence in pecans, walnuts, hazelnuts and cashews. (g) PAC are quantified by non-specific measures in most tree nuts. Further study is needed to characterise the large-molecular-weight polymer linkages in these PAC and subunit constituents.

(h) Except in cashews and pistachios, alkylphenols have not been characterised in tree nuts.

(i) For pecan flavonoids, the literature reports values with three-orders of magnitude difference in the content of these phytochemicals, thus providing uncertainty to their actual values.

(j) The lignan content of macadamias is unreported despite their being detected in all other tree nuts.

(k) The quantitative data on juglone in pecans are outdated and should be reanalysed with updated methods.

(1) The sphingolipid content of tree nuts could be improved by using more specific methods of quantification.

(m) Studies validating quantification methods (for example, extraction conditions, recovery, stability) of tree nut phytochemicals are lacking.

\section{Future directions}

Accurate quantitative analysis and reporting of phytochemicals are critical to understanding the health-promoting properties and quality parameters of tree nuts. Of course, this issue applies to all plant foods and a broader and more detailed discussion of this topic is warranted in future forums. Opportunities should be created to support efforts to: (i) submit available data for inclusion in phytochemical databases, (ii) improve the confidence of values in these databases, and (iii) fill knowledge gaps. Accuracy and reliability of data collection should be improved by designing well-controlled studies. The criteria for sampling, analytical methodology and quality control as proposed by Holden et al. represent a good starting point ${ }^{(72)}$. Quantification of freely extractable and bound polyphenols should also be considered ${ }^{(73)}$. Extraction conditions should also be optimised for each tree nut or food matrix. Since commercial analytical standards of high purity are lacking for many polyphenols, particularly tannins, suitable standards may need to be isolated before quantification. For future research efforts, a very good potential exists for finding new phenolic or other phytochemicals in tree nuts. Particularly, studies of macadamia, Brazil nut and pine nut phenolics are sparse. Further, there is incomplete knowledge of alkylphenols, stilbenes, HT and PAC in most tree nuts. Therefore, new research investigations in these areas are likely to be productive. While increasing the accuracy and precision of database values is an important goal, it is worth appreciating that the extraordinary complexity of the phytochemical composition of tree nuts and other plant foods could detract from one of the principal uses of these resources, 
i.e. determining nutrient intake from dietary assessments. Instruments for dietary assessment themselves typically conflate closely related foods and do not distinguish between factors such as cultivars. Interestingly, for application to nutrient databases, Milbury et al. ${ }^{(74)}$ summarised the flavonoid content of different almond genotypes by combining their analytical data with information on market sales to provide a basis for averaging nutrient composition values.

\section{Factors affecting phytochemical content}

Phytochemical contents vary extensively between and within nut genotypes. Variables imposed before (intrinsic) and after (extrinsic) harvesting contribute to this variation. While the tree nut genotype contributes to the majority of pre-harvest variation in nut phytochemical content, environmental stresses including starvation, infection, predation and UV light also modulate the capacity for phytochemical synthesis. Some particular phytochemicals are influenced by processing (roasting, irradiation and pasteurisation) and storage (temperature and duration) after nuts are harvested. Data for these factors vary among tree nuts. Thus, the following sections are organised by genotype and other pre- or post-harvest factors where supporting studies are available. It is worthwhile noting that the varying phytochemical composition of tree nuts may influence not only their putative health benefits to consumers but also the agricultural properties of the nut tree, such as resistance to moulds and pests.

\section{Pre-harvest factors}

Genetics (variety). The pathways for the synthesis of phytochemicals are dictated principally by genetics. The data presented in the 'Phytochemical databases with tree nuts' and 'Tree nut phytochemical values reported after database publication' sections reveal a large difference in phytochemical profiles between tree nuts. This variation is a consequence of divergence of gene expression between nut types. In addition, there is a substantial diversity in phytochemical synthesis between genotypes. Comprehensive research investigating the effect of genotype on phytochemical content within each tree nut type has not been conducted. A few studies have reported that the genotype effect was significant on total phenol, flavonoid and 'total antioxidant capacity' (TAC) of almonds, hazelnuts, pecans, pistachios and walnuts.

Genetics (variety): almonds. There are three available almond studies examining the effect of genotype on phytochemical content in California almonds. Milbury et al. ${ }^{(74)}$ observed that among seven almond genotypes, total phenol content in Padre almonds at $241 \mathrm{mg} / 100 \mathrm{~g}$ GAE was $100 \%$ larger than in Fritz almonds (Table 13). TAC in almond skins of seven genotypes also varied with a $142 \%$ difference between the highest and the lowest ferric-reducing antioxidant power (FRAP) value. Bolling et $a l .{ }^{(32)}$ and Milbury et al. ${ }^{(74)}$ characterised twenty flavonoids and phenolic acids in seven and eight California almond genotypes, respectively. They found the sum of their concentrations varied $2 \cdot 7$-fold between almond genotypes. They also found that polyphenol profile between almond genotypes was able to be discriminated based on their heredity (Fig. 5). Particularly, the concentration of total phenols in Sonora almonds was $170 \%$ larger than in Fritz almonds. Hughey et al. ${ }^{(29)}$ also reported that Carmel almonds had $47 \%$ more flavonoid content than Nonpareil almonds. Similarly, a study of ten Portuguese almond genotypes showed a 4 - and 18-fold difference in flavonoids and total phenols between genotypes, respectively ${ }^{(75)}$.

The concentration of individual flavonoids in almonds depends upon the genotype. Bolling et al. ${ }^{(32)}$ found that Sonora almonds are particularly high in catechin and isorhamnetin-3-O-glucoside compared with Nonpareil almonds. Thus, genotype affects the type and concentration of flavonoids synthesised in almonds. The genotype effect on other phytochemicals in almonds remains to be determined.

Genetics (variety): hazelnuts. Amaral et al. ${ }^{(76)}$ observed that phytosterol contents differed between

Table 13. Polyphenol content, total phenols and ferric-reducing antioxidant power (FRAP) values of seven almond genotypes over 3 years $^{(74)}$

(Mean values and standard deviations)

\begin{tabular}{|c|c|c|c|c|c|c|c|}
\hline \multirow[b]{2}{*}{ Genotype (skin \%) } & \multirow[b]{2}{*}{$n$} & \multicolumn{2}{|c|}{$\begin{array}{l}\text { Polyphenols } \\
(\mathrm{mg} / 100 \mathrm{~g})\end{array}$} & \multicolumn{2}{|c|}{$\begin{array}{l}\text { Total phenols } \\
\text { (mg GAE/100 g) }\end{array}$} & \multicolumn{2}{|c|}{ FRAP $(\mu \mathrm{mol}$ TE/100 g) } \\
\hline & & Mean & SD & Mean & SD & Mean & $\mathrm{SD}$ \\
\hline Sonora & 3 & $10 \cdot 7^{a}$ & $2 \cdot 90$ & $159^{a}$ & 21 & $891^{\mathrm{a}}$ & 139 \\
\hline Carmel & 9 & $7 \cdot 96^{\mathrm{a}, \mathrm{b}}$ & 1.44 & $101^{a}$ & 30 & $888^{a}$ & 216 \\
\hline Mission & 3 & $6 \cdot 91^{\mathrm{b}}$ & 0.51 & $102^{a}$ & 60 & $609^{a, b}$ & 267 \\
\hline Butte & 9 & $6 \cdot 62^{\mathrm{b}, \mathrm{c}}$ & 0.79 & $58^{b}$ & 7 & $368^{b}$ & 78 \\
\hline Nonpareil & 9 & $6 \cdot 19^{\mathrm{b}, \mathrm{c}}$ & 0.78 & $108^{a}$ & 25 & $645^{a, b}$ & 87 \\
\hline Monterey & 3 & $4 \cdot 88^{\mathrm{C}}$ & 1.08 & $81^{b}$ & 12 & $530^{\mathrm{b}}$ & 53 \\
\hline Fritz & 3 & $3.96^{c}$ & $2 \cdot 34$ & $58^{b}$ & 7 & $565^{b}$ & 274 \\
\hline
\end{tabular}

GAE, gallic acid equivalents; TE, Trolox equivalents.

a,b,c Mean values within a column with unlike superscript letters are significantly different $(P \leq 0.05$; ANOVA and Tukey's honestly significant difference (HSD) test). 


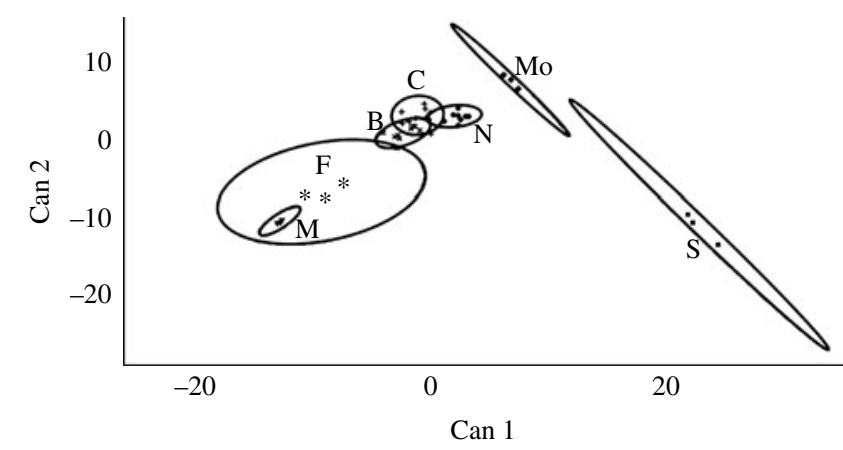

Fig. 5. Canonical discriminant analysis of almond genotypes based on polyphenol content and antioxidant activity ${ }^{(32)}$. M, Mission; F, Fritz; B, Butte; C, Carmel; N, Nonpareil; Mo, Monterey; S, Sonora; Can 1, first canonical variable; Can 2, second canonical variable. Data represent the first two canonical variables of almond samples by genotype with $80 \%$ confidence ellipses.

nineteen hazelnut genotypes harvested from Vila Real in 2001. The concentration of total sterols ranged from 134 to $263 \mathrm{mg} / 100 \mathrm{~g}$ oil, and the concentration of the main phytosterol, $\beta$-sitosterol ranged from 108 to $220 \mathrm{mg} / 100 \mathrm{~g}$ oil. Cristofori et al. ${ }^{(77)}$ reported that the total phenol content of hazelnuts varied among seven genotypes. Jakopic et al. ${ }^{(78)}$ reported that the total phenol content of hazelnuts ranged from 70 to $478 \mathrm{mg}$ GAE/kg kernels, with an average of $189.5 \mathrm{mg} / \mathrm{kg}$ among twenty hazelnut genotypes harvested in Maribor, Slovenia. Further, they reported that the concentrations of myricetin-3-O-rhamnoside ranged from 0.2 to $2 \cdot 1 \mathrm{mg} / \mathrm{kg}$, with an average of $1.0 \mathrm{mg} / \mathrm{kg}$ kernels; quercetin-3-O-rhamnoside ranged from 1.4 to $9.9 \mathrm{mg} / \mathrm{kg}$, with an average of $3.6 \mathrm{mg} / \mathrm{kg}$; quercetinpentoside ranged from 0.05 to $0.15 \mathrm{mg} / \mathrm{kg}$, with an average of $0.08 \mathrm{mg} / \mathrm{kg}$; catechin ranged from 1.4 to $26.3 \mathrm{mg} / \mathrm{kg}$, with an average of $7.3 \mathrm{mg} / \mathrm{kg}$; gallic acid ranged from 0.09 to $0.52 \mathrm{mg} / \mathrm{kg}$, with an average of $0.26 \mathrm{mg} / \mathrm{kg}$; and protocatechuic acid ranged from 0.5 to $2.9 \mathrm{mg} / \mathrm{kg}$, with an average of $0.9 \mathrm{mg} / \mathrm{kg}$. Solar \& Stampar ${ }^{(79)}$ also reported that epicatechin content ranged from 14.0 to $74.5 \mathrm{mg} / \mathrm{kg}$ kernels in sixteen hazelnut genotypes harvested in Slovenia. The impact of genotype on polyphenols in hazelnuts is consistent with that on almonds.

Genetics (variety): pecans. Vilarreal-Lozoya et al. ${ }^{(80)}$ and Lombaridini et $a l{ }^{\left({ }^{81)}\right.}$ reported that total phenol content of five pecan genotypes (Desirable, Kanza, Nacono, Pawnee and Shawnee) grown in Texas (USA) varied almost 1-fold, with concentrations ranging between 62 and $113 \mathrm{mg} / 100 \mathrm{~g}$ defatted kernels. Vilarreal-Lozoya et $a l .{ }^{(80)}$ also reported that TAC values in defatted kernel of five pecan genotypes (Desirable, Kanza, Nacono, Pawnee and Shawnee) grown in Texas were significantly different from one another. Hydrophilic ORAC values and 2,2-diphenyl-2-picrylhydrazyl (DPPH) values of the Kanza genotype, which were the highest, were 119 and $67 \%$ larger than those of the lowest Desirable genotype. The relationship of genotype to individual flavonoid content has not been studied.

Genetics (variety): pistachios. Tokusoglu et al. ${ }^{(48)}$ reported that the trans-resveratrol content varied between five pistachio genotypes (Uzun, Kirmizi, Halebi, Ohadi and Sirrt) grown in Turkey. Uzun pistachios with $9 \mu \mathrm{g}$ transresveratrol/100 g were $17 \cdot 5$-fold lower than the content of Ohadi pistachios.

Genetics (variety): walnuts. The genotype effect on walnut polyphenols has not been reported, but its effect is suggested by other data; for example, the tocopherol and fatty acid composition in nine walnut genotypes (Franquette, Lara, Marbot, Mayette, Mellanaise, Parisienne, Arco, Hartley and Rego) harvested in northeastern Portugal were different $^{(82,83)}$. Further, walnut leaves collected from the same nine genotypes have varied contents of nine constituent polyphenols ${ }^{(84)}$.

Amaral et al. ${ }^{(85)}$ examined the phytosterol content of six walnut genotypes grown in northeastern Portugal (Table 14). The total sterol content of the Marbot genotype was $68 \%$ greater than the Parisienne genotype. The difference was not ascribed to a geographic effect because walnut trees of all genotypes were planted in the same orchard.

\section{Environment}

In addition to genetics, environmental factors can regulate the synthesis of phytochemicals. These factors are either climatic (soil type, sun exposure (UV irradiation), rainfall) or agronomic (organic $v$. convention cultivation, irrigation, fertilisation, nut yield/tree, etc.). Particularly, environmental stress, i.e. exposure to light, infestation or drought, has a considerable impact on polyphenol synthesis because of their phytoalexin function, defending against predators and pathogens, and in providing reproductive

Table 14. Genotype effect on sterol contents in walnuts ${ }^{(85)}$

\begin{tabular}{|c|c|c|c|c|}
\hline Genotype & $\begin{array}{l}\text { Campesterol } \\
\text { (mg/100 g oil) }\end{array}$ & $\begin{array}{c}\beta \text {-Sitosterol } \\
\text { (mg/100 g oil) }\end{array}$ & $\begin{array}{l}\Delta 7 \text {-Avenasterol } \\
\text { (mg/100 g oil) }\end{array}$ & $\begin{array}{c}\text { Total from eight } \\
\text { sterols (mg/100 g oil) }\end{array}$ \\
\hline Franquette & $8 \cdot 6$ & $138 \cdot 3$ & $7 \cdot 3$ & $159 \cdot 0$ \\
\hline Marbot & $9 \cdot 6$ & $175 \cdot 7$ & $11 \cdot 4$ & $202 \cdot 6$ \\
\hline Mayette & $8 \cdot 1$ & 151.4 & $13 \cdot 3$ & $179 \cdot 6$ \\
\hline Mellanaise & $6 \cdot 5$ & $109 \cdot 8$ & $7 \cdot 3$ & $127 \cdot 1$ \\
\hline Lara & $10 \cdot 8$ & $170 \cdot 6$ & 9.8 & $196 \cdot 1$ \\
\hline Parisienne & $6 \cdot 1$ & $109 \cdot 3$ & 2.5 & $120 \cdot 7$ \\
\hline
\end{tabular}


Table 15. Effect of harvest season on polyphenol content and antioxidant activity of Butte, Carmel and Nonpareil almonds ${ }^{(32)}$

(Mean values and standard deviations, $n$ 9)

\begin{tabular}{|c|c|c|c|c|c|c|}
\hline \multirow[b]{2}{*}{ Season } & \multicolumn{2}{|c|}{$\begin{array}{l}\text { Polyphenols } \\
\text { (mg/100 g) }\end{array}$} & \multicolumn{2}{|c|}{$\begin{array}{l}\text { Total phenols } \\
\text { (mg GAE/100 g) }\end{array}$} & \multicolumn{2}{|c|}{$\begin{array}{l}\text { FRAP } \\
(\mu \mathrm{mol} \text { TE } / 100 \mathrm{~g})\end{array}$} \\
\hline & Mean & SD & Mean & SD & Mean & SD \\
\hline 2005 & $7 \cdot 019^{a}$ & 0.103 & 87 & 26 & 584 & 207 \\
\hline 2006 & $6 \cdot 284^{b}$ & 0.124 & 96 & 39 & 616 & 251 \\
\hline 2007 & $6 \cdot 117^{b}$ & 0.959 & 87 & 38 & 630 & 200 \\
\hline
\end{tabular}

GAE, gallic acid equivalents; FRAP, ferric-reducing antioxidant power; TE, Trolox equivalents.

${ }^{\mathrm{a}, \mathrm{b}}$ Mean values within a column with unlike superscript letters are significantly different ( $P \leq 0.05$; ANOVA and Tukey's honestly significant difference (HSD) test).

advantage as attractants of pollinators and seed dispensers. The impact of environmental factors on nut phytochemicals has not been systematically investigated.

Almonds. Seasonal factors include climate, soil nutrition, infestation and related parameters. Bolling et al. ${ }^{\text {(29) }}$ examined total phenols, polyphenols and FRAP values in almonds across three harvest seasons and found that season had a small but statistically significant effect on total polyphenol content in almonds while there were not differences in total phenols and FRAP values (Table 15). These results suggest the overall phenol production, as well as TAC, may not fluctuate importantly between seasons. However, a more robust study with a larger sample size is necessary to confirm the stability of phenol production between seasons.

Pecans. De la Rosa et al. ${ }^{(86)}$ characterised the content of ellagic, gallic, $p$-hydroxybenzoic and protocatechuic acids and TAC in pecans grown in three locations of the State of Chihuahua, Mexico. They found that growing location did not affect TAC measured by ORAC, DPPH, 2,2'-azino-bis(3-ethylbenzothiazolin-6-sulfonic acid (ABTS) and hydroxyl radical-scavenging assay. The content of the four phenolic acids also was not different, with average values of 5, 220, 55 and $21 \mathrm{mg} / \mathrm{g}$, respectively.

Hedin et $a l .^{(61)}$ reported that juglone contents in pecans were increased along with harvesting months (from June to September) within a season from 47.9 (June and July) to $116 \mathrm{mg} / 100 \mathrm{~g}$ (August and September).

Pistachios. The effect of geographic location on the phytochemical content of pistachios has been studied in Europe. Bellomo \& Fallico ${ }^{(87)}$ measured anthocyanins, chlorophylls and xanthophylls in pistachios collected from Italy and Turkey in the 2001-2002 season (Table 16) and found that pistachios from Turkey generally had a much lower phytochemical content. However, Grippi et al. ${ }^{(49)}$ found in a small study with twelve pistachio samples that Sicilian pistachios collected from orchards in Bronte and Agrigento, regions about 100 miles $(160 \mathrm{~km})$ apart, had comparable total resveratrol content at $0.7 \mathrm{mg} / 100 \mathrm{~g}$ kernels. The geographic effect on phytosterols in pistachios was also reported by the same group, where the distribution of nine phytosterols in pistachios harvested in Italy (Bronte and Agrigento), Turkey, Greece and Iran differed ${ }^{(88)}$. $\beta$-Sitosterol, the main phytosterol found in pistachios, was found at 85.5 and $88.0 \%$, respectively, with $\Delta 5$-avenasterol at 9.2 and $5.7 \%$, respectively, in Italy and Iran.

Walnuts. Hedin et al. ${ }^{(61)}$ reported the juglone content in black walnuts was increased from 79 to $193 \mathrm{mg} / 100 \mathrm{~g}$ along with harvesting months (from June to September) within a season. Amaral et $a l^{\left({ }^{(84)}\right.}$ found, in walnut leaves, that there was a seasonal effect on nine polyphenol compounds (3-caffeoylquinic, 3-p-coumaroylquinic and 4-p-coumaroylquinic acids, quercetin 3-galactoside, quercetin 3-arabinoside, quercetin 3-xyloside, quercetin 3-rhamnoside, a quercetin 3-pentoside derivative and a kaempferol 3-pentoside derivative), implicating a seasonal effect on walnut polyphenols.

\section{Post-harvest factors}

There are complex and interactive effects of agronomic practices on the production of phytochemicals in many crops, i.e. organic $v$. conventional cultivation. Precision deficit irrigation practices were found to enhance lycopene and other carotenoids in watermelons and tomatoes, but at the risk of lowered productivity. However, the effect of agronomic practices on tree nuts is not available, so research into this topic is warranted.

After harvesting, nuts are commonly subjected to different treatments before consumption, including pasteurisation, bleaching, roasting, irradiation and storage. Among the tree nuts where research has been conducted, there are significant effects of post-harvesting processing treatments on phytochemicals in almonds, pecans, pistachios and walnuts.

Almonds. Almonds are currently subjected to mandatory pasteurisation or roasting treatments before consumption due to food safety concern. Bolling et al. ${ }^{(89)}$ showed that three pasteurisation procedures did not change TAC of phytochemicals in almond skins, measured by FRAP and total phenol assays, or individual flavonoid concentrations (Table 17). However, because there were large

Table 16. Geographic effect on anthocyanins, chlorophylls and xanthophylls in pistachios ${ }^{(87)}$

\begin{tabular}{lcccc}
\hline Country & $\begin{array}{c}\text { Cyanidin-3-galactoside } \\
(\mathrm{mg} / 100 \mathrm{~g})\end{array}$ & $\begin{array}{c}\text { Chlorophyll-a } \\
(\mathrm{mg} / 100 \mathrm{~g})\end{array}$ & $\begin{array}{c}\text { Chlorophyll-b } \\
(\mathrm{mg} / 100 \mathrm{~g})\end{array}$ & $\begin{array}{c}\text { Lutein } \\
(\mathrm{mg} / 100 \mathrm{~g})\end{array}$ \\
\hline Turkey & 28.7 & 1.8 & 0.7 & 1.8 \\
Italy (Bronte) & $28 \cdot 1$ & 10.7 & 3.6 & 3.8 \\
Italy (Agrigento) & 42.6 & 12.0 & 4.0 & 3.5 \\
\hline
\end{tabular}


Table 17. Effect of pasteurisation and roasting on almond skin flavonoids and phenolic acids, total phenols and ferric-reducing antioxidant power (FRAP) values ${ }^{(89)}$

(Mean values and standard deviations)

\begin{tabular}{|c|c|c|c|c|c|c|c|c|c|}
\hline \multirow[b]{2}{*}{ Samples } & \multicolumn{3}{|c|}{ Flavonoids, phenolics acids ( $\mu \mathrm{g} / \mathrm{g}$ skin) } & \multicolumn{3}{|c|}{ Total phenols (mg GAE/g skin) } & \multicolumn{3}{|c|}{ FRAP ( $\mu \mathrm{mol}$ TE/g skin) } \\
\hline & Mean & SD & $\%$ of raw samples & Mean & SD & $\%$ of raw samples & Mean & SD & $\%$ of raw samples \\
\hline Raw & 1809 & 117 & 100 & $27 \cdot 6$ & $13 \cdot 8$ & 100 & 210 & 102 & 100 \\
\hline PPO & 1583 & 110 & 88 & $16 \cdot 7$ & 3.6 & 61 & 114 & 43 & 55 \\
\hline $\mathrm{S} 1$ & 1725 & 57 & 96 & 19.5 & 11.4 & 71 & 144 & 83 & 69 \\
\hline S2 & 1594 & 245 & 88 & $17 \cdot 6$ & 11.4 & 64 & 95.4 & 64 & 45 \\
\hline Raw & 1557 & 183 & 100 & $25 \cdot 1$ & 9.4 & 100 & 179 & 71 & 100 \\
\hline Roasted & 1537 & 146 & 99 & $18 \cdot 5^{\star}$ & 5.5 & 74 & $119^{*}$ & 40 & 66 \\
\hline
\end{tabular}

GAE, gallic acid equivalents; TE, Trolox equivalents; PPO, polypropylene oxide; S1, steam treatment 1; S2, steam treatment 2.

* Significance was assessed by a paired $t$ test for roasted samples $(n 12)(P \leq 0.05)$.

variations in study outcomes within the pasteurisation treatments, a more robust study investigating the pasteurisation effect on almond phytochemicals is warranted. It has been recognised that roasting is potentially destructive to phytochemicals. Bolling et al. ${ }^{(89)}$ found that roasting decreased total phenol content and FRAP values in almonds, but did not change concentrations of flavonoids. This discrepancy might be attributed to specific breakdown of heat-labile antioxidant constituents other than flavonoids.

During long-term storage, nutrients in nuts are subjected to changes of temperature and humidity. Bolling et al. ${ }^{(89)}$ hypothesised that long-term storage could have a detrimental impact on the polyphenol content and TAC of almonds. In contrast, total polyphenol and total phenol content and FRAP values of raw almond skins were found to increase with storage duration, independent of storage temperature at 4 or $23^{\circ} \mathrm{C}$ (Fig. 6). Further, individual polyphenol compounds appeared to have different degrees of increase (Fig. 7). In particular, p-hydroxybenzoic acid increased about 400-fold after 15 months of storage.

Cashews. The kernel of the cashew nut is removed from the shell by a process known as shelling, which can be achieved by various methods such as drying, steam roasting, oil-bath roasting, or cooking under high-pressure steam. Trox et al. ${ }^{(90)}$ examined that the effect of oil-bath roasting, steam roasting, drying, open pan roasting and Flores hand-cracking on carotenoid and tocopherol contents in kernels. They reported that shelling, roasting and drying promoted decreases in $\beta$-carotene, lutein, and $\alpha$ - and $\gamma$-tocopherol as compared with raw kernels, with widely varied magnitude of reductions (Table 18). The open pan roasting in general exhibited the highest level of decrease in phytochemicals probably due to the direct action of fire; and the Flores hand-cracking method led to a lower level of reduction of phytochemicals. In order to preserve phytochemicals, the selection of the shelling method for cashew nuts is critical.

Hazelnuts. Schmitzer et al. ${ }^{(91)}$ reported that roasting had a negative effect on individual phenolics but not on the total phenolic content and TAC (determined by $\mathrm{DPPH}$ ) of hazelnuts. They found that the roasting decreased protocatechulic acid, phloretin-2-O-glucoside, catechin and epicatechin contents in whole hazelnuts of six genotypes harvested in Maribor, Slovenia. The percentage reduction in the four phenolic compounds could be as
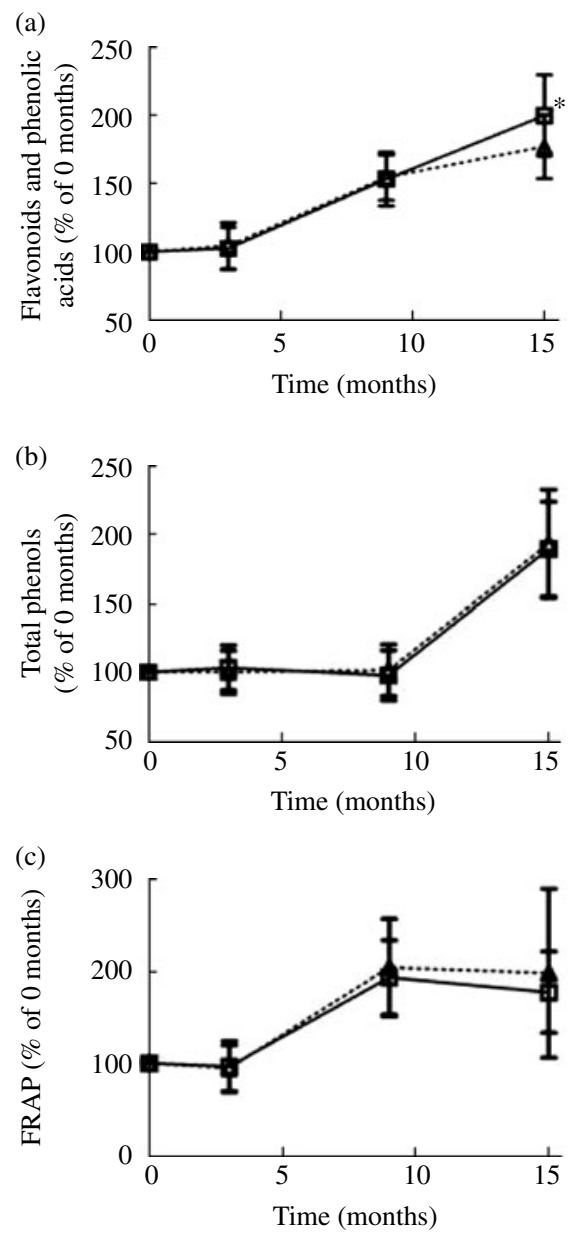

Fig. 6. Storage of raw almonds in darkness at $4^{\circ} \mathrm{C}(-\Delta-)$ and $23^{\circ} \mathrm{C}(-\square-)$ for 15 months increased flavonoids and phenolic acids determined by liquid chromatography-MS (a), total phenols (b) and ferric-reducing antioxidant power (FRAP) (c) of almond skins ${ }^{(89)}$. Values are means $(n 13)$, with standard errors represented by vertical bars, representing seven almond varieties. ${ }^{*}$ Mean value was significantly different from that at $4^{\circ} \mathrm{C}(P \leq 0.05)$. 
high as $84 \%$. On the other hand, gallic acid content was increased by the roasting, with the magnitude of the increase being from 2 to $818 \%$. The increase in gallic acid after roasting might be ascribed to degradation of HT.

Pecans. Food irradiation is a food safety procedure to eliminate pathogenic microbial contaminations and involves exposure of food to different sources of ionising energy. Villarreal-Lozoya et $a l^{\left({ }^{92}\right)}$ studied the effect of irradiation on phytochemical contents in Kanza and Desirable pecans collected in the autumn of 2004 in Texas. Pecan kernels were treated with $0,1.5$ and $3 \mathrm{kGy}$ irradiation, followed by storage at $40^{\circ} \mathrm{C}$ and 55 to $60 \%$ relative humidity for up to $134 \mathrm{~d}$. They found that this accelerated storage condition promoted decreases in total phenols (about 20\% reduction as compared with the initial values), condensed tannins (about 30\% reduction), and TAC measured by ORAC (no significant changes) and DPPH (about 15\% reduction for the Desirable genotype), while irradiation itself before storage did not have any major effect on the studied measures. The storage effect on phenol compounds in pecans is largely consistent with those found in almonds.

Pistachios. After harvesting, pistachios are typically sun dried in Italy. Ballistreri et al. ${ }^{(40)}$ found that sun drying for $3 \mathrm{~d}$ decreased total phenol content and the majority of determined flavonoids and stilbenes in Bronte pistachios collected in Italy in 2007 (Table 19). The magnitudes of reduction ranged from 30 to $83 \%$.

Gentile et $a l^{(43)}$ reported that roasting at $160^{\circ} \mathrm{C}$ for 40 min deceased total phenols, TAC, PAC and trans-resveratrol content in Bronte pistachios collected in Sicily in 2005 (Table 20). Interestingly, isoflavones in pistachios were not degraded by the roasting treatment. These results are consistent with those observed in almonds that roasting decreased FRAP and total phenol values and did not alter flavonoid concentrations ${ }^{(89)}$.

Pistachios in China are often bleached before retailing. Seeram et $a l .{ }^{(42)}$ examined the effect of bleaching treatment with different concentrations of $\mathrm{H}_{2} \mathrm{O}_{2}$ for $1 \mathrm{~min}$, followed by $20 \mathrm{~min}$ of roasting at $60^{\circ} \mathrm{C}\left(140^{\circ} \mathrm{F}\right)$ on anthocyanins and TAC of in-shell pistachios. They found that bleaching significantly decreased cyanidin-glucoside and -galactoside concentrations and TAC measured by the Trolox equivalent antioxidant capacity (TEAC) assay in pistachio skins in a $\mathrm{H}_{2} \mathrm{O}_{2}$ concentration-dependent manner (Table 21). They also found that roasting alone significantly deceased cyanidin-glucoside, cyanidin-galactoside and TAC values compared with raw pistachio skins.

Bellomo et al. ${ }^{(50)}$ examined the storage effect on chlorophyll-a and -b and lutein in pistachios at 10,25 and $37^{\circ} \mathrm{C}$ for up to 14 months. The pistachios were collected from Bronte, Italy in 2003. In general, these phytochemicals decreased over time, dependent on storage temperatures. On average, chlorophyll-a and $-b$ and lutein were decreased by 50,30 and $44 \%$ at 14 months, respectively.
Walnuts. Sze-Tao et al. ${ }^{(93)}$ observed that 5 min of roasting at $204^{\circ} \mathrm{C}$ caused a small but statistically significant decrease in tannins (catechin polymers) in walnuts (585 $v$. $520 \mathrm{mg}$ catechin equivalents $/ 100 \mathrm{~g}$ dry weight). This result is similar to the effect of roasting pistachios at $160^{\circ} \mathrm{C}$ for $40 \mathrm{~min}$ where the content of PAC decreased by $87 \%$.
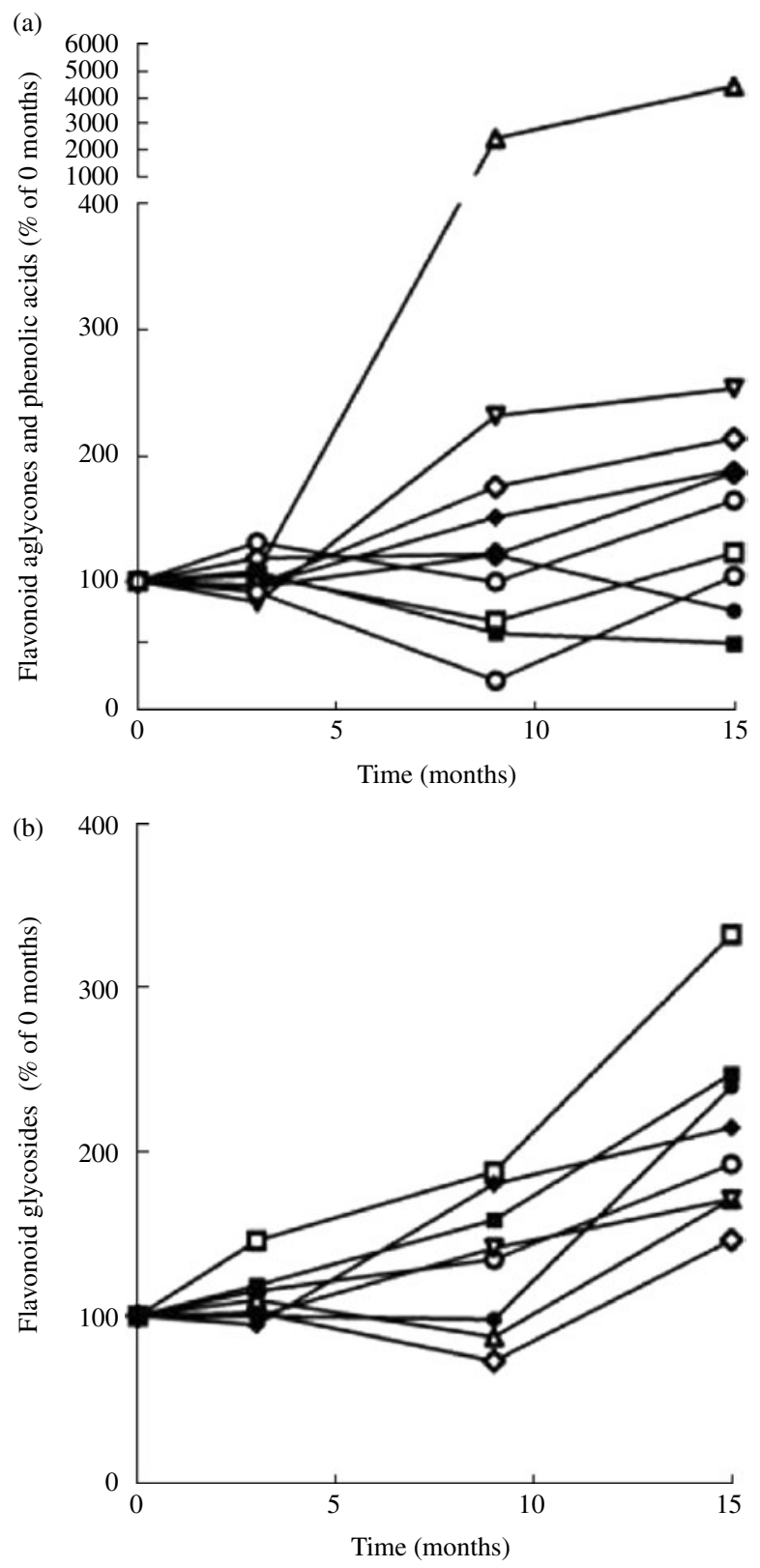

Fig. 7. (a) Changes to flavonoid aglycone and phenolic acid content in almond skins upon storage at $23^{\circ} \mathrm{C}$ for 15 months ${ }^{(89)} .(--), p$-Hydroxybenzoic acid; $(\neg-)$, dihydroxykaempferol; $(\neg)$, kaempferol; $(\longrightarrow-)$, eriodic-

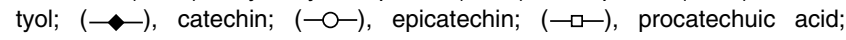
$(\multimap-)$, isorhamnetin; (- - ), quercetin; (-—), naringenin. (b) Changes to flavonoid glycoside content in almond skins upon storage at $23^{\circ} \mathrm{C}$ for 15 months ${ }^{(89)}$. ( $\left.\square-\right)$, Quercetin-3-O-galactoside; ( --$)$, isorhamnetin3-O-glucoside; (-), kaempferol-3-O-glucoside; $(\longrightarrow)$, isorhamnetin-3-Orutinoside; (-○), naringenin-7-O-glucoside; $(-\nabla-)$, kaempferol-3-O-rutinoside; $(\neg-)$, kaempferol-3-O-galactoside; $(\smile-)$, quercetin-3-O-rutinoside. 


\section{Methodology of phytochemical determinations}

Extraction of the constituent phytochemicals from the nut matrix is required before their determination by any analytic method. Given that a standardised methodology for different groups of phytochemicals has not been established, there are diverse protocols for their extraction and determination. A few common organic solvents, typically methanol, acetone, acetonitrile or ethyl acetate, have been generally employed to extract polyphenols from nuts; in addition, hexane and chloroform have been employed to extract more lipid-soluble compounds. Each solvent extracts a different profile of phytochemicals due to their wide range of polarity. Thus, different extraction solvents may explain some of the inconsistency in reported values of phytochemicals in tree nuts. Even though there are a few reports discussing the impact of extraction methodology on phytochemical content of foods, establishing a standardised protocol for phytochemical extraction would provide a platform to facilitate valid comparisons in phytochemical data reported by different laboratories and enhance confidence level in values summarised in nutrient databases.

In addition to the influence of extraction protocol, the instruments employed to determine phytochemicals in extracts have a profound effect on the accuracy of reported values. However, there is no published report comparing the consistency of phytochemical values using a wide spectrum of analytical instruments, such as liquid chromatography (LC)-MS, LC-MS/MS, and HPLC with spectrophotometric, fluorometric or electrochemical detection.

\section{Almonds and hazelnuts}

Almonds. Since organic solvents employed to extract polyphenols do not closely reflect the physiological bioaccessibility of polyphenols in the gastrointestinal tract, Chen \& Blumberg ${ }^{(94)}$ compared the amount of total phenols extracted from almond skins using acidified methanol solvent ( $\mathrm{M}$; acetic acid-methanol-water, 3·7:50:46.3 by vol.) and a gastrointestinal mimic juice solvent (GI, containing pepsin and pancreatic juice). They found that the total phenol content of almond skins was different by 4.8 -fold (M v. GI solvent: 91.2 v. $14.9 \mu \mathrm{mol} \mathrm{GAE} / \mathrm{g}$ or 15.5 v. $2.5 \mathrm{mg} / \mathrm{g} ; P \leq 0.05$ ). Further, the LC-MS chromatograms of almond skin polyphenols extracted with $M$ and GI at the same GAE concentration showed qualitatively different profiles of flavonoids, largely because of the absence in the GI solvent of catechin, epicatechin, kamperfol-3-O-glucoside, kaemperfol-3-O-galactoside, dihydroxy-kampferol, quercetin-3-O-glucoside, quercetin-3-O-galacoside, rutin, isorhamnetin, kaempferol, naringenin, quercetin and eriodictyol (Fig. 8). These results raise again the question regarding what extraction solvent(s) should be used for characterising nut phytochemicals. 
Table 19. Content of phenolics ( $\mathrm{mg} / 100 \mathrm{~g} \mathrm{DM})$ in edible pistachio kernels of Bronte Pistacia vera ${ }^{(40)}$

\begin{tabular}{lcc}
\hline Phenolic compound & Fresh & Sun dried \\
\hline Total phenols $(\mathrm{mg} \mathrm{GAE} / 100 \mathrm{~g})$ & 349 & 185 \\
Cyanidin-3-galactoside $(\mathrm{mg} / 100 \mathrm{~g})$ & $48 \cdot 6$ & $20 \cdot 4$ \\
Cyanidin-3-glucoside $(\mathrm{mg} / 100 \mathrm{~g})$ & $15 \cdot 1$ & 3.9 \\
Daidzein $(\mathrm{mg} / 100 \mathrm{~g})$ & $3 \cdot 3$ & $2 \cdot 1$ \\
Genistein $(\mathrm{mg} / 100 \mathrm{~g})$ & $3 \cdot 2$ & $2 \cdot 0$ \\
Daidzin $(\mathrm{mg} / 100 \mathrm{~g})$ & $1 \cdot 7$ & $1 \cdot 2$ \\
Quercetin $(\mathrm{mg} / 100 \mathrm{~g})$ & $1 \cdot 7$ & $1 \cdot 4$ \\
Eriodictyol $(\mathrm{mg} / 100 \mathrm{~g})$ & $1 \cdot 4$ & 0.9 \\
Luteolin $(\mathrm{mg} / 100 \mathrm{~g})$ & 1.4 & 0.9 \\
Genistin $(\mathrm{mg} / 100 \mathrm{~g})$ & $1 \cdot 1$ & $1 \cdot 1$ \\
Naringenin $(\mathrm{mg} / 100 \mathrm{~g})$ & $0 \cdot 2$ & 0.1 \\
Trans-resveratrol $(\mathrm{mg} / 100 \mathrm{~g})$ & 1.2 & 0.2 \\
\hline
\end{tabular}

GAE, gallic acid equivalents.

Hazelnuts. Alasalvar et al. ${ }^{(53)}$ compared the extraction efficiency of $80 \%$ ethanol and $80 \%$ acetone on total phenols in hazelnuts. They found that $80 \%$ acetone was more efficient to extract phenols and tannins than $80 \%$ ethanol (Table 22). Ghirardello et al. ${ }^{(95)}$ compared extraction of phenolic compounds using three different solvent mixtures $(80 \%(\mathrm{v} / \mathrm{v})$ ethanol, methanol, and acetone with water) at different temperatures. Consistent with the results from Alasalvar et al. ${ }^{(53)}$, they found that $80 \%$ acetone at $50^{\circ} \mathrm{C}$ exhibited the best extracting capacity with the highest total phenol content and TAC.

\section{Phytosterols and sphingolipids}

Miraliakbari \& Shahidi ${ }^{(70)}$ studied the effect of extraction solvents on the yield of phytosterols and sphingolipids in seven tree nuts. They employed two protocols: (i) three sequential extractions with hexane or (ii) three sequential extractions with chloroform once and then chloroformmethanol (1/1, v/v) twice. They reported that the chloroform-methanol solvent system produced a higher oil yield for all tree nuts than hexane (Table 23). They also measured sphingolipids and sterols including 22-nordehydrocholesterol, cholesterol, cholestanol, campesterol, stigmasterol, 24-methylenecholesterol, $\beta$-sitosterol, $\beta$-sitostanol and $\Delta 5$-avenasterol. They found that chloroform-methanol was equal or more effective in extracting sphingolipids and phytosterols than hexane, for example, with chloroform-methanol providing a $24 \%$ larger sterol yield in pine nuts than methanol (Table 24).

\section{Summary of factors affecting phytochemicals \\ Current knowledge}

The phytochemical content of tree nuts has been reported in a few databases and many articles in the scientific literature. Nevertheless, our understanding on the effect or preand post-harvest factors on these values is quite limited. Table 25 summarises the effect of some of these impact factors on the values of eleven phytochemical classes, total phenols and TAC. Information in this area appears to be unavailable for Brazil nuts, cashews, macadamias and pine nuts. The data on almonds, hazelnuts, pecans, pistachios and walnuts indicate that most pre- and postharvest factors have a significant effect on their polyphenol, total phenols and TAC. The storage effect on the changes in polyphenol content and TAC in almonds and pecans does not appear consistent. In addition, the effect of roasting on decreases in nut polyphenol concentration appears depends on the type of polyphenol; for example, isoflavones (pistachios), flavanols (almonds) and flavonols (almonds) are more resistant to heat than anthocyanins, PAC and trans-resveratrol (pistachios). Thus, more studies are necessary to elucidate the influence of these impact factors on the quality and quantity of nut phytochemicals.

To date, there has been no effort to conduct a systematic investigation into the impact of different methodologies for phytochemical extraction and quantification. A few studies have shown that the choice of solvents used for extracting polyphenols and phytosterols significantly affects the results obtained. For example, the capacity of acetone $v$. ethanol for extracting polyphenols is markedly different, although hexane and chloroform-methanol appear to possess similar efficacy in extracting phytosterols. Further complicating this situation are inter-laboratory comparisons of results obtained from different instruments even when similar solvent systems are employed. Although a systematic comparison of phytochemical values produced by different instruments is not available, inherent differences in instrument performance on parameters such as sensitivity, accuracy and precision would be expected to contribute substantially to differences between reports from multiple laboratories.

\section{Knowledge gaps}

The present review of tree nuts has identified several gaps in the knowledge about the effect of impact factors on tree nut phytochemicals and TAC, including:

(a) The genotype of each tree nut has a significant impact on phytochemical content as has been shown for almond flavonoids, pecan total phenol and pistachio trans-resveratrol. Studies investigating

Table 20. The effect of roasting on total phenols, total antioxidant capacity (TAC) and flavonoids in edible kernels of pistachios ${ }^{(43)}$

\begin{tabular}{lcc}
\hline & Raw & Roasted \\
\hline Total phenols $(\mathrm{mg} \mathrm{GAE} / 100 \mathrm{~g})$ & 175 & 65 \\
TAC $(\mathrm{TEAC})(\mu \mathrm{mol} \mathrm{TE} / 100 \mathrm{~g})$ & 2755 & 1085 \\
Proanthocyanidins $(\mathrm{mg} / 100 \mathrm{~g})$ & 268 & 34 \\
Trans-resveratrol $(\mu \mathrm{g} / 100 \mathrm{~g})$ & 12 & Undetectable \\
Isoflavones $(\mathrm{mg} / 100 \mathrm{~g})$ & 7.1 (genistein & 8.9 \\
& + daidzein) & \\
\hline
\end{tabular}

GAE, gallic acid equivalents; TEAC, Trolox equivalent antioxidant capacity; $\mathrm{TE}$, Trolox equivalents. 
Table 21. Effect of bleaching and roasting on anthocyanins and total antioxidant capacity values in pistachio skins ${ }^{(42)}$

\begin{tabular}{|c|c|c|c|c|c|c|}
\hline \multirow[b]{2}{*}{$\mathrm{H}_{2} \mathrm{O}_{2}(\%)$} & \multicolumn{3}{|c|}{ Raw } & \multicolumn{3}{|c|}{ Roasted } \\
\hline & $\begin{array}{c}\text { Cyanidin-3-galactoside } \\
(\mu \mathrm{g} / \mathrm{g})\end{array}$ & $\begin{array}{l}\text { Cyanidin-3-glucoside } \\
(\mu \mathrm{g} / \mathrm{g})\end{array}$ & $\begin{array}{c}\text { TEAC } \\
(\mu \mathrm{mol} / \mathrm{g} \text { Trolox })\end{array}$ & $\begin{array}{l}\text { Cyanidin-3-galactoside } \\
(\mu \mathrm{g} / \mathrm{g})\end{array}$ & $\begin{array}{l}\text { Cyanidin-3-glucoside } \\
(\mu \mathrm{g} / \mathrm{g})\end{array}$ & $\begin{array}{c}\text { TEAC } \\
(\mu \mathrm{mol} / \mathrm{g} \text { Trolox })\end{array}$ \\
\hline 0 & 696 & 209 & 946 & 462 & 87 & 725 \\
\hline 0.5 & 457 & 74 & 932 & 87 & 33 & 464 \\
\hline 1 & 341 & 43 & 934 & 70 & 26 & 466 \\
\hline 5 & 103 & 7 & 931 & 28 & 3 & 456 \\
\hline 15 & 33 & 3 & 453 & 10 & 2 & 439 \\
\hline 25 & 6 & 0 & 434 & 3 & 0 & 378 \\
\hline
\end{tabular}

TEAC, Trolox equivalent antioxidant capacity.

the effect of genotype on other tree nuts, as well as their principal phytochemical classes, have not been conducted. This information is important to establishing the reliable values for including in phytochemical databases so that estimates of health benefits from nut consumption (and differences between types of nuts) can be investigated in observational studies. Further, this information can help to guide the breeding of more economically valuable and more nutritious nut genotypes.

(b) Growing location and season have been found to affect some phytochemical classes in almonds, pecans, pistachios and walnuts. However, there is a need to better quantify and understand how important these factors are in altering the phytochemical profile and content of these and other tree nuts. Such data can assist in the improvement of agricultural practices for producing more (or less) phytochemicals for outcomes such as nut appearance, growth, resistance to pests and health benefits. (c) In general, post-harvest treatments, such as sun drying, storage, hot water blanching, high temperature roasting, irradiation and bleaching, appear to decrease the phytochemical content from that found in raw nuts. However, exceptions to this generalisation have been noted. For example, almond polyphenols are increased during storage and roasting almonds or pistachios does not affect flavonoids or isoflavones, respectively, but does decrease total phenols and TAC in both nuts. Thus, further research on post-harvest factors is required to improve the information provided to phytochemical databases and for considerations of modifying these methods to control the phytochemical content and composition of tree nuts.

(d) Establishing standard methods for extracting and quantifying nut phytochemicals would provide a number of benefits to researchers, including the creation of accurate and reliable values for comparisons between nuts and genotypes and also understanding

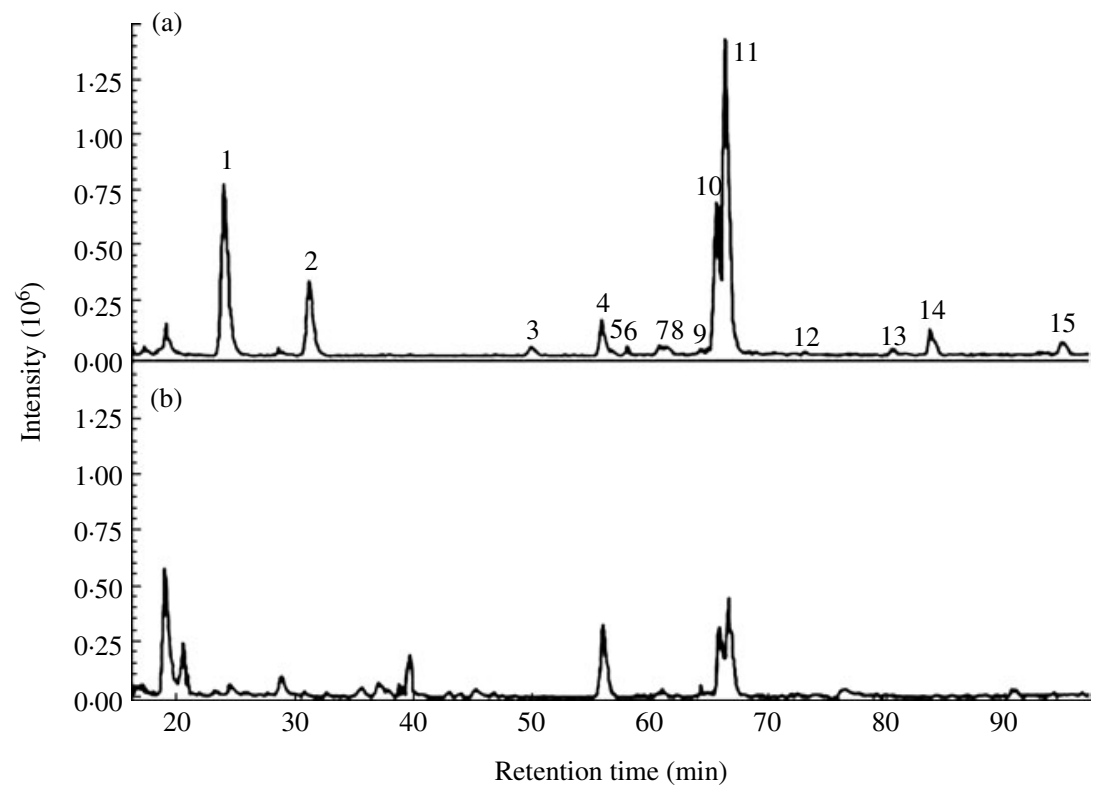

Fig. 8. Typical liquid chromatography - MS/MS extracted ion chromatograms of almond skin polyphenolics from (a) acidified methanol extraction and (b) gastrointestinal juice mimic extraction ${ }^{(94)}$. Peak numbers correspond to compounds as (1) catechin, (2) epicatechin, (3) quercetin-3-O-galactoside, (4) naringein-7-O-glucoside, (5) rutin, (6) quercetin-3-O-glucoside, (7) dihydroxylkaempferol, (8) kaempfer-3-O-galactoside, (9) kaempferol-3-O-glucoside, (10) kaempferol-3-O-rutinoside, (11) isorhamnetin-3-O-runtinoside, (12) eriodictyol, (13) quercetin, (14) naringenin and (15) isorhamnetin. 
Table 22. Total phenols, condensed tannins and total antioxidant capacity measured by Trolox equivalent antioxidant capacity (TEAC) in $1 \mathrm{~g}$ dry extracts of hazelnuts ${ }^{(53)}$

\begin{tabular}{lccc}
\hline Solvent & $\begin{array}{c}\text { Total phenols }(\mathrm{mg} \text { catechin } \\
\text { equivalents/g dry extract) }\end{array}$ & $\begin{array}{c}\text { Condensed tannins (mg catechin } \\
\text { equivalents/g dry extract) }\end{array}$ & $\begin{array}{c}\text { TEAC (mmol Trolox } \\
\text { equivalents/g) }\end{array}$ \\
\hline $80 \%$ ethanol & 23 & 41 & 0.20 \\
$80 \%$ acetone & 103 & 320 & 0.62 \\
\hline
\end{tabular}

the stability of these values under varying agricultural and environmental conditions. Further, undertaking this effort with newer HPLC and LC-MS technologies will substantially upgrade the quality of data obtained earlier from less accurate and precise values associated with spectrophotometric assays.

\section{Future directions}

The phytochemical content of tree nuts is subject to the influence of many pre- and post-harvest factors, including genetics, environment, cultivation practice, climate, processing and storage. Further, the results from the determination of nut phytochemicals are dependent upon the methodology used to extract and measure them. Thus, the phytochemical values available in the published databases and in many reports in the scientific literature are limited by the absence of all the relevant information necessary to interpret them. Steps can be made through new research, thorough characterisation of the tree nut (including genotype, harvest location and year, processing, etc.), use of HPLC and LC-MS technologies, and careful reporting to provide more accurate, complete and precise information about their phytochemical profiles. This information can then be employed to optimise the production and processing of tree nuts for growth and appearance as well as for human health.

Evidence for bioactivity and health effects of tree nuts in humans

In general, tree nuts are a rich source of unsaturated MUFA and PUFA and are low in SFA. They also contain dietary fibre, protein, micronutrients, plant sterols and several other polyphenolic phytochemical compounds. Many polyphenols possess relatively potent antioxidant, anti-atherosclerotic, anti-inflammatory, anti-mutagenic, anti-tumour and anti-viral activities ${ }^{(96)}$, but further research is necessary to elucidate and quantify the contributions of phytochemicals to health promotion and disease prevention. In humans, evidence of the bioactivity and health effects attributable to the bioactive constituents in nuts is emerging, but remains largely unknown. A few human studies of the bioavailability of tree nut phytochemicals have been published, but observational and intervention studies targeted to health outcomes have only been undertaken with whole tree nuts. As most nut phytochemicals belong to classes for which bioactivity has been demon- strated in vitro, in animal models and human studies, it is reasonable to hypothesise that they contribute to the health benefits associated with the consumption of tree nuts. For example, after feeding $73 \mathrm{~g}$ almonds/d to hyperlipidaemic subjects, Jenkins et $a l^{(97)}$ attributed the reduction in biomarkers of oxidative stress to their phenolic antioxidant content as no increase in serum vitamin $\mathrm{E}$ was obtained with the intervention. While the MUFA and PUFA content of nuts certainly plays an important role in their beneficial impact on lipid profiles, it is possible that the effect of polyphenols on hepatic cholesterol absorption, TAG assembly and secretion, and the processing of lipoproteins in plasma may also contribute substantially to this health outcome ${ }^{(98)}$. Nonetheless, the health benefits demonstrated following the consumption of whole nuts cannot be specifically attributed to any of their nutrient components, including their phytochemical composition. To date, no human studies have been designed to understand the direct effect of nut phytochemicals on health outcomes. However, clinical studies which examine separately the impact of nut components such as the skin, meat and oil, while incorporating appropriate control groups could provide important new information in this regard and should be undertaken.

\section{Observational studies}

Data from large observational studies consistently show that regular nut consumption lowers the risk for several conditions in which oxidative stress may play a role. Four major epidemiological studies, including the Nurses' Health Study ${ }^{(99)}$, the Physicians' Health Study ${ }^{(100)}$, the Iowa Women's Health Study ${ }^{(101,102)}$ and the Adventist Health Study ${ }^{(103-106)}$, have all shown that frequent nut consumption is associated with a decreased risk of CHD events. Compared with individuals who ate nuts less than

Table 23. Oil yields of seven tree nuts extracted with hexane or chloroform-methanol ${ }^{(70)}$

\begin{tabular}{lcc}
\hline & \multicolumn{2}{l}{ Oil yield $(\%, w / w)$} \\
\cline { 2 - 3 } Tree nut & Hexane & \multicolumn{2}{c}{ Chloroform-methanol } \\
\hline Almonds & 51.2 & 53.5 \\
Brazil nuts & 67.4 & 68.9 \\
Hazelnuts & 60.4 & 61.9 \\
Pecans & 71.5 & 73.4 \\
Pine nuts & 73.9 & 75.1 \\
Pistachios & 52.3 & 54.1 \\
Walnuts & 70.6 & 72.5 \\
\hline
\end{tabular}


Table 24. Yields of sphingolipids and sterols extracted by hexane or chloroform-methanol (CM) in seven tree nuts ${ }^{(70)}$ (Mean values)

\begin{tabular}{|c|c|c|c|c|c|c|}
\hline \multirow[b]{2}{*}{ Tree nut } & \multirow[b]{2}{*}{$\begin{array}{l}\text { Sphingolipids } \\
\text { (g/100 g oil) }\end{array}$} & \multicolumn{5}{|c|}{ Sterols (mg/g oil) } \\
\hline & & Campsterol & Stigmasterol & $\beta$-Sitosterol & $\Delta 5$-Avenasterol & Total from nine sterols \\
\hline \multicolumn{7}{|l|}{ Almonds } \\
\hline Hexane & 0.53 & 0.09 & 0.19 & $2 \cdot 30$ & $0 \cdot 10$ & 2.68 \\
\hline $\mathrm{CM}$ & $0.63^{*}$ & 0.09 & 0.19 & $2 \cdot 29$ & 0.11 & 2.75 \\
\hline \multicolumn{7}{|l|}{ Brazil nuts } \\
\hline Hexane & 0.83 & 0.12 & 0.22 & $1 \cdot 11$ & $0 \cdot 10$ & 1.92 \\
\hline $\mathrm{CM}$ & $0.91^{*}$ & $0 \cdot 15^{*}$ & 0.23 & $1 \cdot 12$ & 0.11 & 2.06 \\
\hline \multicolumn{7}{|l|}{ Hazelnuts } \\
\hline Hexane & 0.26 & 0.17 & 0.32 & 1.07 & 0.07 & 1.85 \\
\hline $\mathrm{CM}$ & 0.32 & 0.17 & 0.39 & $1 \cdot 10$ & 0.09 & 1.99 \\
\hline \multicolumn{7}{|l|}{ Pecans } \\
\hline Hexane & 0.48 & 0.22 & 0.44 & 1.67 & $0 \cdot 10$ & $2 \cdot 62$ \\
\hline $\mathrm{CM}$ & 0.55 & 0.24 & $0.60^{*}$ & 1.75 & 0.11 & 2.76 \\
\hline \multicolumn{7}{|l|}{ Pine nuts } \\
\hline Hexane & 0.45 & 0.19 & 0.13 & 1.20 & 0.06 & 1.29 \\
\hline $\mathrm{CM}$ & 0.57 & 0.22 & 0.15 & $1 \cdot 12$ & 0.07 & $1.60^{\star}$ \\
\hline \multicolumn{7}{|l|}{ Pistachios } \\
\hline Hexane & 0.73 & 0.20 & $0 \cdot 10$ & $1 \cdot 14$ & 0.13 & 1.52 \\
\hline $\mathrm{CM}$ & $0.82^{*}$ & 0.21 & 0.11 & $1 \cdot 19$ & 0.15 & 1.69 \\
\hline \multicolumn{7}{|l|}{ Walnuts } \\
\hline Hexane & 0.54 & 0.18 & 0.33 & $2 \cdot 16$ & 0.17 & 2.92 \\
\hline $\mathrm{CM}$ & $0.68^{*}$ & 0.19 & 0.35 & $2 \cdot 25$ & 0.18 & 2.99 \\
\hline
\end{tabular}

* Mean values differ between the two solvent systems in the same nut.

once per week, it was estimated that consuming a $1 \mathrm{oz}$ ( $28 \mathrm{~g})$ serving of nuts five or more times per week conferred a reduction in CHD risk of up to $50 \%(104,107,108)$.

Frequent nut intake has also been associated with a reduction in all-cause mortality. In the Iowa Women's Health Study ${ }^{(101)}$, the consumption of two or more $28.5 \mathrm{~g}$ servings per week was associated with a $12 \%$ reduction in all-cause mortality compared with those who consumed $<$ one serving per month (95\% CI $0 \cdot 77$, 0.99; $P_{\text {trend }}=0.047$ ), while in the Adventist Health Study subjects who consumed nuts five times per week had an $18 \%$ lower risk of death compared with those who consumed nuts less than one serving per week $(95 \% \mathrm{CI}$ $0 \cdot 70,0.96 ; P<0 \cdot 01)^{(105)}$.

Nut consumption was also associated with a lower risk of developing hypertension in the Physicians' Health Study $\mathrm{I}^{(109)}$ and type 2 diabetes mellitus in the Nurses' Health Study ${ }^{(110)}$. In this same cohort, a positive correlation with adiponectin ${ }^{(111)}$, a biomarker of cardioprotection, and an inverse correlation with CVD risk $^{(112)}$ was observed among women with type 2 diabetes mellitus.

Evidence from the Multi-Ethnic Study of Atherosclerosis (MESA) suggests that frequent nut consumption is inversely correlated with biomarkers of inflammation and endothelial dysfunction, including C-reactive protein (CRP), IL-6, fibrinogen and soluble intercellular adhesion molecule-1 (sICAM-1) ${ }^{(113,114)}$. Normal endothelial function is impaired by inflammatory cytokines and cell adhesion molecules, and, in prospective studies, these biomarkers have been shown to be independent predictors of $\mathrm{CVD}^{(115-117)}$. More recently, Gopinath et al. ${ }^{(118)}$ reported a protective role of nuts against inflammatory disease mortality (primarily respiratory, nervous or digestive system diseases) in the Blue Mountains Eye Study cohort.

To date, no observational studies have directly correlated the intake of nuts with plasma total antioxidant activity or biomarkers of oxidative stress, as these measures are not routinely assessed in large cohorts. Similarly, no observational studies have correlated the intake of specific nut bioactive constituents with biomarkers of disease risk.

\section{Clinical trials}

Lipid-lowering effects. Most randomised clinical trials of nuts conducted thus far have focused on the hypocholesterolaemic effects of whole nuts, and not their individual constituents. In a systematic review of twenty-three intervention studies, Mukuddem-Petersen et al. ${ }^{(119)}$ reported the consumption of 50-100 g of almonds, groundnuts, pecans or walnuts five or more times per week, as part of a heart-healthy diet moderate in fat (about 35\% of energy), significantly lowered total cholesterol (2-16\%) and LDL-cholesterol (2-19\%) in both normo- and hyperlipidaemic individuals compared with control diets without nuts or with a different fatty acid profile. Similarly, in their review, Griel \& Kris-Etherton ${ }^{(120)}$ concluded that tree nuts, i.e. walnuts, almonds, macadamias, pecans, pistachios and hazelnuts, reduced LDL-cholesterol 3-19\% when compared with Western and lower-fat diets. Subsequent trials of hazelnuts ${ }^{(121,122)}$, pistachios $^{(123)}$, macadamia nuts $^{(124)}$ and Brazil nuts ${ }^{(125)}$ have also confirmed their hypocholesterolaemic effect. 

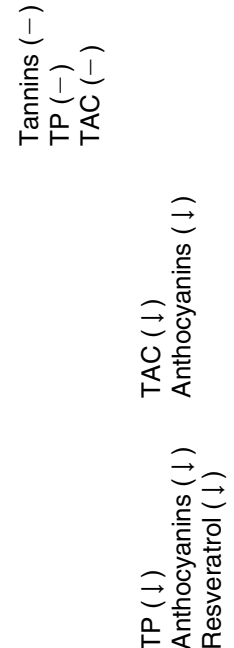

In a pooled analysis of twenty-five nut intervention trials, Sabate et al. ${ }^{(126)}$ determined a mean intake of $67 \mathrm{~g} / \mathrm{d}$ lowered total cholesterol 5\%, LDL-cholesterol 7\%, LDL:HDL 8\%, total cholesterol:HDL 6\% and TAG 10\% (among those with initial levels $\geq 150 \mathrm{mg} / \mathrm{dl}(1500 \mathrm{mg} / \mathrm{l})$ only). Their analysis also revealed that the lipid-lowering effect of nuts was dose-related and greatest among subjects with high LDL and low BMI, regardless of the type of nut consumed.

Nuts are rich in chemically related phytosterols, a class of compounds that interfere with intestinal cholesterol absorption which, according to Segura et al. ${ }^{(127)}$ might explain part of the cholesterol-lowering effect of nut intake beyond that attributable to fatty acid exchange. Given the evidence that polyphenols also lower cholesterol absorption ${ }^{(98)}$, it is plausible that there are multiple mechanisms of action and/or potential synergistic effects between the individual nut constituents. However, no definitive studies have examined the extent of the contribution of polyphenols to the observed lipid-lowering effect.

Inflammation and endothelial function. A limited number of human studies have examined the effects of nuts on inflammation, endothelial function and vascular reactivity. In the Prevención con Dieta Mediterránea (PREDIMED) Study of 772 asymptomatic adults, aged $55-80$ years, a Mediterranean diet including nuts $(30 \mathrm{~g} / \mathrm{d})$ reduced levels of circulating IL-6 $(P<0 \cdot 018)$, ICAM-1 $(P<0.003)$ and vascular cell adhesion molecule-1 (VCAM1) from baseline after 3 months, but not $\mathrm{CRP}^{(128)}$. Compared with a low-fat control diet, between-group differences in endothelial function were also observed, but no $P$ values were reported. In this study, lowered fasting glucose $(P=0.039)$, insulin $(P<0.001)$, homeostatic model assessment (HOMA) index $(P<0 \cdot 001)$, and systolic $(P<0 \cdot 001)$ and diastolic blood pressure ( $P=0 \cdot 001)$ were also observed after 3 months with the nut diet when compared with the control diet.

A Mediterranean diet in which $32 \%$ of the energy from MUFA fat was replaced with walnuts improved VCAM-1 status $(P<0.05)$, a circulating marker of endothelial activation, but had no effect on ICAM-1, CRP or homocysteine after 4 weeks when compared with a cholesterol-lowering Mediterranean diet ${ }^{(129)}$. Flow-mediated dilation, a measure of brachial artery vasomotor function and a biomarker of CHD risk, also improved significantly after both acute and chronic walnut feeding in twenty-four hypercholesterolaemic subjects from this cohort ${ }^{(129,130)}$. A similar substitution with pistachios also improved endothelial function $(P<0.002)$ and lowered levels of IL-6 $(P<0.001)$, as well as fasting glucose $(P<0.001)$, with no change in either CRP or TNF- $\alpha$ after 4 weeks in a cohort of thirty-two healthy young men living in a controlled environment ${ }^{(131)}$.

Macadamia nuts, when incorporated into the diet at $15 \%$ of energy $(40-90 \mathrm{~g} / \mathrm{d})$, lowered plasma leucotriene $\mathrm{B}_{4}$ levels from baseline after 4 weeks in seventeen hypercholesterolaemic men ${ }^{(132)}$. A non-significant reduction in 
the plasma thromboxane $\mathrm{B}_{2}$ :prostacyclin $\mathrm{I}_{2}$ ratio was also observed following macadamia nut consumption.

Among healthy adults, incorporating almonds into the diet at 10 and $20 \%$ of energy $(34$ and $68 \mathrm{~g} / 2000 \mathrm{kcal}$ $(8368 \mathrm{~kJ})$, respectively) for 4 weeks lowered CRP when compared with a nut-free control diet, although no dose-response relationship was observed. E-selectin was also significantly lower, but only with the higher almond dose $\mathrm{e}^{(133)}$

A controlled feeding trial incorporating walnuts as a source of $\alpha$-linolenic acid (ALA) demonstrated the antiinflammatory effects of an ALA-rich diet in hypercholesterolaemic subjects $^{(134)}$. In this study, a diet containing about $37 \mathrm{~g}$ walnuts/d and $15 \mathrm{~g}$ walnut oil/d reduced CRP $(P<0.01)$ and ICAM-1 $(P<0.01)$ when compared with an average American diet, while also lowering VCAM-1 $(P<0.01)$ and E-selectin $(P<0.01)$ when compared with a diet high in linoleic acid. This walnut diet also lowered levels of IL- 6 , IL- $6 \beta$ and TNF- $\alpha$ production by peripheral blood mononuclear cells $(P<0.05)^{(135)}$. In contrast, a controlled feeding trial of walnuts and cashews showed no effect on serum $\mathrm{CRP}^{(136)}$ in sixty-four subjects with the metabolic syndrome. While the anti-inflammatory effects shown by Zhao et al. ${ }^{(134,135)}$ were most probably due to the walnut fatty acids, neither feeding trial controlled for the presence of dietary antioxidants or phytochemicals, which alone can make an impact on these biomarkers.

\section{Oxidative stress and antioxidant activity}

In vitro assessment of the TAC of tree nuts, using the ORAC, FRAP, total peroxyl radical-trapping potential (TRAP) and Trolox equivalent antioxidant capacity (TEAC) assays, has been reported in the USDA Oxygen Radical Absorbance Capacity (ORAC) of Selected Foods $^{(6)}$, a FRAP database of over 3100 foods $^{(137)}$ and in selected research reports. However, TAC data specifically on nut skins (pellicles), the location for most nut phytochemicals (except the phytosterols), are not generally available. As these assays are not particularly sensitive to tocopherols (present in the kernel or meat), much of the TAC value of nuts is probably derived from polyphenolic compounds in the skin. Importantly, TAC values correlate little or poorly with in vivo biomarkers of antioxidant status. However, TAC assays appear potentially useful in assessing antioxidant effects in food products, for example, to identify natural replacements for synthetic antioxidants such as butylated hydroxyanisole and butylated hydroxytoluene to promote shelf life and other applications for developing new applications in foods ${ }^{(138)}$.

The effects of nut consumption on antioxidant status and biomarkers of oxidative stress have been reported in a limited number of human intervention studies. Lopez- Uriarte et $a l^{(139)}$ and $\operatorname{Ros}^{(140)}$ reviewed a total of twenty-one clinical studies in which the potential effects of tree nuts on biomarkers of oxidation or antioxidant activity were evaluated.

As most of these studies used whole nuts, rather than nut components (such as the skins which contain much of the polyphenol content or the kernels where the tocopherols are found) or their individual phytochemical constituents, the contribution of these bioactive compounds to these results is unknown. However, when the reported outcomes of these nut studies are considered, it is clear that their effects cannot be due entirely to their MUFA or PUFA content alone.

Early intervention studies comparing a walnut-enriched, high-PUFA diet with a walnut-free, lower-PUFA diet showed no differences in the prevention of LDL oxidation $^{(129,141-143)}$ or $\mathrm{TAC}^{(144)}$ between diets. While the shift to more PUFA in the diet and plasma with walnut consumption could be predicted to increase plasma biomarkers of lipid peroxidation, the absence of an effect may be due to the concurrent intake and bioavailability of walnut phytochemicals, including phenolic compounds and tocopherols. Davis et al. ${ }^{(145)}$ reported no change in plasma antioxidant capacity following the consumption of 63-108 g walnuts or cashews/d for 8 weeks in metabolic syndrome patients. After 6 weeks, no significant changes in TAC (specifically, the ORAC, FRAP and total antioxidant parameter assays), antioxidant status (total plasma phenols, thiols and glutathione peroxidase) or lipid peroxidation (malondialdehyde) were observed with either 21 or $42 \mathrm{~g}$ walnuts/d in a randomised cross-over trial conducted in twenty-one generally healthy men and postmenopausal women aged $\geq 50$ years by McKay et al. ${ }^{(146)}$. Interestingly, a significant reduction in erythrocyte lipid peroxidation was observed in subjects at increased risk for CVD following a diet with $21.4 \mathrm{~g}$ walnuts/d for 5 weeks, when compared with a control diet ${ }^{(147)}$, but this effect was modulated according to each subject's particular paraoxonase (PON1) polymorphism ${ }^{(148)}$.

According to Ros ${ }^{(140)}$, the available evidence suggests that while PUFA-rich nuts confer a neutral or minimal effect on oxidative status, the effects of MUFA-rich nuts are more moderate. Indeed, Fito et al $^{(149)}$ reported a significant reduction in circulating oxidised LDL concentrations among asymptomatic adults, aged 55-80 years, 3 months after consuming a Mediterranean diet including $30 \mathrm{~g}$ whole nuts/d mixed at 50\% walnuts, 25\% almonds and $25 \%$ hazelnuts. Moreover, other chronic feeding studies using low-PUFA nuts, including pecans ${ }^{(150)}$, hazelnuts ${ }^{(151,152)}$, macadamia nuts ${ }^{(132)}$, pistachios ${ }^{(153)}$, almonds $^{(154-156)}$ and Brazil nuts ${ }^{(157,158)}$, all showed either an improvement in oxidation status or increased antioxidant enzyme activity. It is plausible that with lower PUFA intake, the need to protect this oxidisable substrate is reduced and a higher proportion of the nut bioactives are available for other functions.

Some studies have shown that the antioxidant effects of nuts are not limited to reduced lipid peroxidation and 
improved plasma antioxidant capacity. Jenkins et al. ${ }^{(159)}$ reported a significant postprandial increase in serum protein thiol concentrations, reflecting less oxidative damage to proteins, following a meal with $60 \mathrm{~g}$ almonds in a study of fifteen healthy young adults. Similarly, McKay et $a l .{ }^{(146)}$ reported elevated plasma total thiols within $1 \mathrm{~h}$ of consuming either 21 or $42 \mathrm{~g}$ walnuts in a study of twenty-one healthy older adults. Lopez-Uriarte et al. ${ }^{(160)}$ found a significant reduction in DNA damage, measured as urinary 8-oxo-7,8-dihydro-2'-deoxyguanosine, a biomarker of oxidatively modified nucleic acids, after 12 weeks with $30 \mathrm{~g}$ mixed nuts ( $15 \mathrm{~g}$ walnuts, $7 \cdot 5 \mathrm{~g}$ almonds, $7.5 \mathrm{~g}$ hazelnuts) when compared with a nut-free diet in a study of fifty metabolic syndrome patients. Jia et al. ${ }^{(161)}$ and Li et al. ${ }^{(162)}$ both reported significant reductions in oxidative DNA damage among smokers following 4 weeks of almond consumption at $84 \mathrm{~g} / \mathrm{d}$. Li et al. ${ }^{(162)}$ evaluated the effects of almonds $v$. pork $(120 \mathrm{~g} / \mathrm{d})$ in a cohort of sixty male smokers serving in the Chinese army, and compared these effects with thirty non-smokers who consumed the control (pork) diet. After 4 weeks, the amount of DNA strand breaks and urinary 8-hydroxy-deoxyguanosine were significantly lower in the almond-supplemented smokers, compared with the pork-supplemented smokers. Significantly lower urinary malondialdehyde, a biomarker of lipid peroxidation, and higher serum $\alpha$-tocopherol status and activities of superoxide dismutase and glutathione peroxidase were also observed in the almond group. No changes in these biomarkers of oxidative stress were observed in the pork-supplemented non-smokers. Although the authors did not measure the specific contribution of the nut polyphenols or antioxidants to these outcomes, this study does suggest that almonds confer an antioxidant benefit.

\section{Bioavailability studies in humans}

In a randomised, cross-over controlled-feeding trial of twenty-eight hypercholesterolaemic adults, Kay et al. ${ }^{(163)}$ determined that the antioxidant nutrients present in pistachios were bioavailable and associated with decreases in oxidised LDL. After consuming a diet enriched with pistachios at either 10 or $20 \%$ energy from fat for 4 weeks, plasma levels of lutein, $\alpha$-carotene and $\beta$-carotene were significantly higher compared with baseline, while lutein and $\gamma$-tocopherol levels were higher compared with a lower-fat control diet. The increases in serum lutein and $\gamma$-tocopherol following the higher-pistachio diet were modestly associated with decreases in oxidised LDL ( $r-0.36, P=0.06$ and $r-0.35, P=0.08$, respectively) after adjusting for the change in serum LDL-cholesterol.

The acute bioavailability of polyphenols from both walnuts and almonds, as well as a concomitant reduction in plasma lipid peroxidation and increased antioxidant capacity following their consumption, was demonstrated by Torabian et $a l .{ }^{(164)}$ in a randomised, placebo-controlled cross-over study of thirteen healthy adults. The total phenolic content of plasma significantly increased $30 \mathrm{~min}$ after consuming either $81 \mathrm{~g}$ walnuts or $91 \mathrm{~g}$ almonds (blended in water), while no changes were observed following an isoenergetic control meal. Peak phenolic concentrations coincided with a significant reduction at $90 \mathrm{~min}$ in plasma thiobarbituric acid-reactive substances, a measure of lipid peroxidation. Values from the FRAP and both lipophilic and hydrophilic ORAC assays also increased significantly following the consumption of both nut meals, with peak capacity observed at $150 \mathrm{~min}$. No changes in plasma TAC were observed following the control meal.

The acute bioavailability of polyphenols from almond skins alone was determined in two studies by the same group. Urpi-Sarda et $a l{ }^{(47)}$ conducted an initial pilot study in which two healthy adults were given a single dose of almond skin extract containing $884 \mathrm{mg}$ total polyphenols. Plasma was collected for $4.5 \mathrm{~h}$ and urine for $24 \mathrm{~h}$. Several derivatives of epicatechin and conjugated forms of naringenin and isorhamnetin were detected in plasma and urine samples following the consumption of almond skins, as were numerous microbial-derived metabolites of flavonols and hydroxyphenylvalerolactones. The urinary excretion of these microbial metabolites accounted for a larger proportion of the total polyphenol ingested than phase II metabolites of epicatechin, indicating the important role of intestinal bacteria in the metabolism of highly polymerised almond skin polyphenols. In a larger, placebo-controlled study by Bartolome et al. ${ }^{(165)}$ twelve healthy adults were given a single dose of almond skin extract (884 mg total polyphenols) and compared with four adults given a control ( $450 \mathrm{mg}$ cellulose). Concentrations of epicatechin sulfate and naringenin-O-glucuronide in the urine of subjects who consumed the almond skins were significantly higher at 2-6h compared with the control subjects, while isorhamnetin sulfate was higher at 10$24 \mathrm{~h}$, and 5-(hydroxymethoxyphenyl)- $\boldsymbol{\gamma}$-valerolactone was higher at all time points between 2 and $24 \mathrm{~h}$.

The results of these studies demonstrate that almond skin polyphenols are bioavailable in humans and appear as phase-II and microbial-derived metabolites in plasma and urine.

\section{Summary}

In addition to being a rich source of several essential vitamins and minerals, MUFA, PUFA and fibre, tree nuts provide a rich array of phytochemicals that may affect: (i) their cultivation, growth and appearance; (ii) tree nut characteristics during processing and storage; (iii) the promotion of human health; and (iv) their value as a by-product of tree nut processing such as blanching. Although many of these bioactive components remain to be fully identified and characterised in tree nuts, particularly their concentration and profiles as affected by genotype, environmental factors and geography, 
broad classes include the carotenoids, phenolic acids, phytosterols, and polyphenolic compounds such as flavonoids, PAC and stilbenes.

While the number of studies remains limited, available evidence indicates that these phytochemicals are bioaccessible and bioavailable in humans. These two parameters are important, as these phytochemicals have been associated with an array of bioactivities, including antioxidant, anti-inflammatory, anti-proliferative, antiviral, chemopreventive and hypocholesterolaemic actions potentially capable of affecting the initiation and progression of several pathogenic processes.

The present report provides a detailed and up-to-date summary and scientific review of the available data on tree nut phytochemicals. This information has been created and collected in disparate and inconsistent ways, making clear, comparative and comprehensive analysis and interpretation difficult. Nonetheless, the information about tree nut phytochemicals presented here can help to: (i) identify gaps in our knowledge about these compounds; (ii) prepare research strategies relevant to agricultural practices (for example, identifying phytoalexin and secondary metabolite properties in different nut genotypes) and human nutrition (for example, studying synergistic interactions among these compounds and between micronutrients in tree nuts and other foods); (iii) place these ingredients in a comparative context with established phytochemical intakes from fruit, vegetables, whole grains and other plant foods; and (iv) allow for consideration of these compounds as potentially valuable by-products of tree nut processing.

\section{Acknowledgements}

The present review was supported by the USDA Agricultural Research Service Cooperative Agreement no. 581950-7-707. The contents of the present publication do not necessarily reflect the views or policies of the USDA nor does mention of trade names, commercial products or organisations imply endorsement by the US government. Each author has declared to have no conflicts of interest. We thank Maureen Ternus, MS, RD and The International Tree Nut Council Nutrition Research \& Education Foundation for their encouragement of our efforts on tree nut phytochemicals. The authors are grateful to Kerilyn Kimball, Jo Obelsky and Elizabeth Wallet for assistance in manuscript preparation.

B. W. B., C.-Y. O. C., D. L. M. and J. B. B. wrote or contributed to the writing of the manuscript.

The authors declare no conflict of interest.

\section{References}

1. Gu L, Kelm MA, Hammerstone JF, et al. (2004) Concentrations of proanthocyanidins in common foods and estimations of normal consumption. J Nutr 134, 613-617.

2. Gu L, Kelm MA, Hammerstone JF, et al. (2003) Screening of foods containing proanthocyanidins and their structural characterization using LC-MS/MS and thiolytic degradation. J Agric Food Chem 51, 7513-7521.

3. Monagas M, Garrido I, Lebron-Aguilar R, et al. (2007) Almond (Prunus dulcis (Mill.) D.A. Webb) skins as a potential source of bioactive polyphenols. J Agric Food Chem 55, 8498-8507.

4. McClements DJ \& Decker EA (2008) Lipids. In Fennema's Food Chemistry, 4th ed., pp. 155-216 [S Damodaran, KL Parkin and OR Fennema, editors]. Boca Raton, FL: CRC Press.

5. Kornsteiner M, Wagner K-H \& Elmadfa I (2006) Tocopherols and total phenolics in 10 different nut types. Food Chem 98, 381-387.

6. US Department of Agriculture (2010) Database for the oxygen radical absorbance capacity (ORAC) of selected foods, release 2. Nutrient Data Laboratory [updated May 2010]. http://www.ars.usda.gov/nutrientdata

7. US Department of Agriculture (2008) Database for the isoflavone content of selected foods, release 2.0. http:// www.ars.usda.gov/nutrientdata

8. US Department of Agriculture (2007) Database for the flavonoid content of selected foods, release 2.1. http:// www.ars.usda.gov/nutrientdata

9. US Department of Agriculture (2004) Database for the proanthocyanidin content of selected foods. http://www. nal.usda.gov/fnic/foodcomp

10. Harnly JM, Doherty RF, Beecher GR, et al. (2006) Flavonoid content of U.S. fruits, vegetables, and nuts. J Agric Food Chem 54, 9966-9977.

11. Yang J, Liu RH \& Halim L (2009) Antioxidant and antiproliferative activities of common edible nut seeds. $L W T-$ Food Sci Technol 42, 1-8.

12. Kuhnle GG, Dell'Aquila C, Aspinall SM, et al. (2008) Phytoestrogen content of beverages, nuts, seeds, and oils. J Agric Food Chem 56, 7311-7315.

13. Venkatachalam M \& Sathe SK (2006) Chemical composition of selected edible nut seeds. J Agric Food Chem 54, 4705-4714.

14. Prodanov M, Garrido I, Vacas V, et al. (2008) Ultrafiltration as alternative purification procedure for the characterization of low and high molecular-mass phenolics from almond skins. Anal Chim Acta 609, 241-251.

15. Monagas M, Garrido I, Lebron-Aguilar R, et al. (2009) Comparative flavan-3-ol profile and antioxidant capacity of roasted peanut, hazelnut, and almond skins. J Agric Food Chem 57, 10590-10599.

16. Neveu V, Perez-Jiménez J, Vos F, et al. (2010) PhenolExplorer: an online comprehensive database on polyphenol contents in foods. Database 2010, bap024 (epublication 8 January 2010).

17. Wu X, Beecher GR, Holden JM, et al. (2004) Lipophilic and hydrophilic antioxidant capacities of common foods in the United States. J Agric Food Chem 52, 4026-4037.

18. Thompson LU, Boucher BA, Liu Z, et al. (2006) Phytoestrogen content of foods consumed in Canada, including isoflavones, lignans, and coumestan. Nutr Cancer 54, 184-201.

19. Smeds AI, Eklund PC, Sjoholm RE, et al. (2007) Quantification of a broad spectrum of lignans in cereals, oilseeds, and nuts. J Agric Food Chem 55, 1337-1346.

20. Pérez-Jiménez J, Neveu V, Vos F, et al. (2010) Identification of the 100 richest dietary sources of polyphenols: an application of the Phenol-Explorer database. Eur J Clin Nutr 64, Suppl. 3, S112-S120 
21. Pérez-Jiménez J, Fezeu L, Touvier M, et al. (2011) Dietary intake of 337 polyphenols in French adults. Am J Clin Nutr 93, 1220-1228.

22. Saura-Calixto F, Serrano J \& Goñi I (2007) Intake and bioaccessibility of total polyphenols in a whole diet. Food Chem 101, 492-501.

23. US Department of Agriculture Agricultural Research Service (2010) National Nutrient Database for Standard Reference, release 23. http://www.ars.usda.gov/ba/bhnrc/ndl

24. Perry A, Rasmussen H \& Johnson EJ (2009) Xanthophyll (lutein, zeaxanthin) content in fruits, vegetables and corn and egg products. J Food Comp Anal 22, 9-15.

25. EuroFIR (2011) eBasis: Bioactive Substances in Food Information System. European Food Information Resource http://ebasis.eurofir.org/Default.asp (accessed May 2011).

26. Yang J (2009) Brazil nuts and associated health benefits: a review. LWT - Food Sci Technol 42, 1573-1580.

27. John JA \& Shahidi F (2010) Phenolic compounds and antioxidant activity of Brazil nut (Bertholletia excelsa). J Funct Foods 2, 196-209.

28. Malik NS, Perez JL, Lombardini L, et al. (2009) Phenolic compounds and fatty acid composition of organic and conventional grown pecan kernels. J Sci Food Agric 89, 2207-2213.

29. Hughey CA, Wilcox B, Minardi CS, et al. (2008) Capillary liquid chromatography-mass spectrometry for the rapid identification and quantification of almond flavonoids. J Chromatogr A 1192, 259-265.

30. Garrido I, Monagas M, Gomez-Cordoves C, et al. (2008) Polyphenols and antioxidant properties of almond skins: influence of industrial processing. $J$ Food Sci 73, C106-C115.

31. Mandalari G, Tomaino A, Arcoraci T, et al. (2010) Characterization of polyphenols, lipids and dietary fibre from almond skins (Amygdalus communis L.). J Food Comp Anal 23, 166-174.

32. Bolling B, Dolnikowski GG, Blumberg J, et al. (2010) Polyphenol content and antioxidant activity of California almonds depend on cultivar and harvest year. Food Chem 122, 819-825.

33. Bolling B, Dolnikowski GG, Blumberg J, et al. (2010) The influence of roasting, pasteurization, and storage on the polyphenol content and antioxidant capacity of California almond skins. Food Chem 123, 1010-1047.

34. Teets AS, Minardi CS, Sundararaman M, et al. (2009) Extraction, identification, and quantification of flavonoids and phenolic acids in electron beam-irradiated almond skin powder. J Food Sci 74, C298-C305.

35. Chen CY, Milbury PE, Lapsley K, et al. (2005) Flavonoids from almond skins are bioavailable and act synergistically with vitamins $\mathrm{C}$ and $\mathrm{E}$ to enhance hamster and human LDL resistance to oxidation. J Nutr 135, 1366-1373.

36. Frison S \& Sporns P (2002) Variation in the flavonol glycoside composition of almond seedcoats as determined by MALDI-TOF mass spectrometry. J Agric Food Chem 50, 6818-6822.

37. Frison-Norrie S \& Sporns P (2002) Identification and quantification of flavonol glycosides in almond seedcoats using MALDI-TOF MS. J Agric Food Chem 50, 2782-2787.

38. Del Rio D, Calani L, Dall'Asta M, et al. (2011) Polyphenolic composition of hazelnut skin. J Agric Food Chem 59, 9935-9941.

39. Yurttas HC, Schafer HW \& Warthesen JJ (2000) Antioxidant activity of nontocopherol hazelnut (Corylus spp.). J Food Sci 65, 276-280.
40. Ballistreri G, Arena E \& Fallico B (2009) Influence of ripeness and drying process on the polyphenols and tocopherols of Pistacia vera L. Molecules 14, 4358-4369.

41. Seeram NP, Henning SM, Niu Y, et al. (2006) Pistachio skin phenolics: identification, antioxidant capacities and their use as markers of bleaching. Abstracts of Papers from the 231st ACS National Meeting, Atlanta, GA, USA, 26-30 March 2006, no. AGFD-039. Washington, DC: American Chemical Society.

42. Seeram NP, Zhang Y, Henning SM, et al. (2006) Pistachio skin phenolics are destroyed by bleaching resulting in reduced antioxidative capacities. I Agric Food Chem $\mathbf{5 4}$ 7036-7040.

43. Gentile C, Tesoriere L, Butera D, et al. (2007) Antioxidant activity of Sicilian pistachio (Pistacia vera $\mathrm{L}$. var. Bronte) nut extract and its bioactive components. J Agric Food Chem 55, 643-648.

44. Gomez-Caravaca AM, Verardo V, Segura-Carretero A, et al. (2008) Development of a rapid method to determine phenolic and other polar compounds in walnut by capillary electrophoresis-electrospray ionization time-of-flight mass spectrometry. J Chromatogr A 1209, 238-245.

45. Anderson KJ, Teuber SS, Gobeille A, et al. (2001) Walnut polyphenolics inhibit in vitro human plasma and LDL oxidation. J Nutr 131, 2837-2842.

46. Amarowicz R, Troszyoska A \& Shahidi F (2005) Antioxidant activity of almond seed extract and its fractions. I Food Lipids 12, 344-358.

47. Urpi-Sarda M, Garrido I, Monagas M, et al. (2009) Profile of plasma and urine metabolites after the intake of almond [Prunus dulcis (Mill.) D.A. Webb] polyphenols in humans. J Agric Food Chem 57, 10134-10142.

48. Tokusoglu O, Unal MK \& Yemis F (2005) Determination of the phytoalexin resveratrol (3,5,4'-trihydroxystilbene) in peanuts and pistachios by high-performance liquid chromatographic diode array (HPLC-DAD) and gas chromatography-mass spectrometry (GC-MS). J Agric Food Chem 53, 5003-5009.

49. Grippi F, Crosta L, Aiello G, et al. (2008) Determination of stilbenes in Sicilian pistachio by high-performance liquid chromatographic diode array (HPLC-DAD/FLD) and evaluation of eventually mycotoxin contamination. Food Chem 107, 483-488.

50. Bellomo MG, Fallico B \& Muratore G (2009) Stability of pigments and oil in pistachio kernels during storage. Int J Food Sci Technol 44, 2358-2364.

51. Li L, Tsao R, Yang R, et al. (2006) Polyphenolic profiles and antioxidant activities of heartnut (Juglans ailanthifolia Var. cordiformis) and Persian walnut (Juglans regia L.). J Agric Food Chem 54, 8033-8040.

52. Shahidi F, Alasalvar C \& Liyana-Pathirana CM (2007) Antioxidant phytochemicals in hazelnut kernel (Corylus avellana L.) and hazelnut byproducts. J Agric Food Chem 55, 1212-1220.

53. Alasalvar C, Karamac M, Amarowicz R, et al. (2006) Antioxidant and antiradical activities in extracts of hazelnut kernel (Corylus avellana L.) and hazelnut green leafy cover. J Agric Food Chem 54, 4826-4832.

54. Wijeratne S, Amarowicz R \& Shahidi F (2006) Antioxidant activity of almonds and their by-products in food model systems. J Am Oil Chem Soc 83, 223-230.

55. Wijeratne SS, Abou-Zaid MM \& Shahidi F (2006) Antioxidant polyphenols in almond and its coproducts. J Agric Food Chem 54, 312-318.

56. Reiter RJ, Manchester LC \& Tan DX (2005) Melatonin in walnuts: influence on levels of melatonin and total antioxidant capacity of blood. Nutrition 21, 920-924. 
57. Lercker G, Strocchi A \& Conte LS (1977) The presence of cardanol in cashew-nut oil. Appl Spectrom Masse (SM) Reson Magn Nucl (RMN) Ind Aliment lSymp Int Comm Int Ind Agric Aliment] 1977, 165-177.

58. Paramashivappa R, Kumar PP, Vithayathil PJ, et al. (2001) Novel method for isolation of major phenolic constituents from cashew (Anacardium occidentale L.) nut shell liquid. J Agric Food Chem 49, 2548-2551.

59. Trevisan MT, Pfundstein B, Haubner R, et al. (2006) Characterization of alkyl phenols in cashew (Anacardium occidentale) products and assay of their antioxidant capacity. Food Chem Toxicol 44, 188-197.

60. Colaric M, Veberic R, Solar A, et al. (2005) Phenolic acids, syringaldehyde, and juglone in fruits of different cultivars of Juglans regia L. J Agric Food Chem 53, 6390-6396.

61. Hedin PA, Langhans VE \& Graves CH (1979) Identification of juglone in pecan as a possible factor of resistance to Fusicladium effusum. J Agric Food Chem 27, 92-94.

62. Borazjani A, Graves CH Jr \& Hedin PA (1985) Occurrence of juglone in various tissues of pecan and related species. Phytopathology 75, 1419-1421.

63. Cerda B, Tomas-Barberan FA \& Espin JC (2005) Metabolism of antioxidant and chemopreventive ellagitannins from strawberries, raspberries, walnuts, and oak-aged wine in humans: identification of biomarkers and individual variability. J Agric Food Chem 53, 227-235.

64. Fukuda T, Ito H \& Yoshida T (2003) Antioxidative polyphenols from walnuts (Juglans regia L.). Phytochemistry $\mathbf{6 3}$, 795-801.

65. Fukuda T, Ito $\mathrm{H} \&$ Yoshida $\mathrm{T}$ (2004) Effect of the walnut polyphenol fraction on oxidative stress in type 2 diabetes mice. Biofactors 21, 251-253.

66. Ito H, Okuda T, Fukuda T, et al. (2007) Two novel dicarboxylic acid derivatives and a new dimeric hydrolyzable tannin from walnuts. J Agric Food Chem 55, 672-679.

67. Shimoda H, Tanaka J, Kikuchi M, et al. (2008) Walnut polyphenols prevent liver damage induced by carbon tetrachloride and d-galactosamine: hepatoprotective hydrolyzable tannins in the kernel pellicles of walnut. J Agric Food Chem 56, 4444-4449.

68. Zhang Z, Liao L, Moore J, et al. (2009) Antioxidant phenolic compounds from walnut kernels (Juglans regia L.). Food Chem 113, 160-165.

69. Miraliakbari H \& Shahidi F (2008) Oxidative stability of tree nut oils. J Agric Food Chem 56, 4751-4759.

70. Miraliakbari H \& Shahidi F (2008) Lipid class compositions, tocopherols and sterols of tree nut oils extracted with different solvents. J Food Lipids 15, 81-96.

71. Miraliakbari H \& Shahidi F (2008) Antioxidant activity of minor components of tree nut oils. Food Chem 111, 421-427.

72. Holden J, Bhagwat S \& Patterson K (2002) Development of a multi-nutrient data quality evaluation system. I Food Comp Anal 15, 339-348.

73. Arranz S, Saura-Calixto F, Shaha S, et al. (2009) High contents of nonextractable polyphenols in fruits suggest that polyphenol contents of plant foods have been underestimated. J Agric Food Chem 57, 7298-7303.

74. Milbury PE, Chen CY, Dolnikowski GG, et al. (2006) Determination of flavonoids and phenolics and their distribution in almonds. J Agric Food Chem 54, 5027-5033.

75. Barreira JC, Ferreira IC, Oliveira MB, et al. (2008) Antioxidant activity and bioactive compounds of ten Portuguese regional and commercial almond cultivars. Food Chem Toxicol 46, 2230-2235.

76. Amaral J, Casal S, Citová I, et al. (2006) Characterization of several hazelnut (Corylus avellana L.) cultivars based in chemical, fatty acid and sterol composition. Eur Food Res Technol 222, 274-280

77. Cristofori V, Ferramondo S, Bertazza G, et al. (2009) Nut quality and sensory evaluation of hazelnut cultivars. Acta Hortic 845, 657-664.

78. Jakopic J, Petkovsek MM, Likozar A, et al. (2011) HPLC-MS identification of phenols in hazelnut (Corylus avellana L.) kernels. Food Chem 124, 1100-1106.

79. Solar A \& Stampar F (2011) Characterisation of selected hazelnut cultivars: phenology, growing and yielding capacity, market quality and nutraceutical value. J Sci Food Agric 91, 1205-1212.

80. Villarreal-Lozoya JE, Lombardini L \& Cisneros-Zevallos L (2007) Phytochemical constituents and antioxidant capacity of different pecan [Carya illinoinensis (Wangenh.) K. Koch] cultivars. Food Chem 102, 1241-1249.

81. Lombardini L, Villarreal-Lozoya JE \& Cisneros-Zevallos L (2009) Antioxidant properties of pecan kernels. Acta Hortic 841, 91-96.

82. Amaral JS, Alves MR, Seabra RM, et al. (2005) Vitamin E composition of walnuts (Juglans regia L.): a 3-year comparative study of different cultivars. I Agric Food Chem 53, 5467-5472.

83. Amaral JS, Cunha SC, Alves MR, et al. (2004) Triacylglycerol composition of walnut (Juglans regia L.) cultivars: characterization by HPLC-ELSD and chemometrics. J Agric Food Chem 52, 7964-7969.

84. Amaral JS, Valentao P, Andrade PB, et al. (2008) Do cultivar, geographical location and crop season influence phenolic profile of walnut leaves? Molecules 13, 1321-1332.

85. Amaral JS, Casal S, Pereira JA, et al. (2003) Determination of sterol and fatty acid compositions, oxidative stability, and nutritional value of six walnut (Juglans regia L.) cultivars grown in Portugal. J Agric Food Chem 51, 7698-7702.

86. de la Rosa LA, Alvarez-Parrilla E \& Shahidi F (2010) Phenolic compounds and antioxidant activity of kernels and shells of Mexican pecan (Carya illinoinensis). J Agric Food Chem 59, 152-162.

87. Bellomo MG \& Fallico B (2007) Anthocyanins, chlorophylls and xanthophylls in pistachio nuts (Pistacia vera) of different geographic origin. J Food Comp Anal 20, 352-359.

88. Arena E, Campisi S, Fallico B, et al. (2007) Distribution of fatty acids and phytosterols as a criterion to discriminate geographic origin of pistachio seeds. Food Chem 104, 403-408.

89. Bolling BW, Blumberg JB \& Oliver Chen CY (2010) The influence of roasting, pasteurisation, and storage on the polyphenol content and antioxidant capacity of California almond skins. Food Chem 123, 1040-1047.

90. Trox J, Vadivel V, Vetter W, et al. (2010) Bioactive compounds in cashew nut (Anacardium occidentale L.) kernels: effect of different shelling methods. J Agric Food Chem 58, 5341-5346.

91. Schmitzer V, Slatnar A, Veberic R, et al. (2011) Roasting affects phenolic composition and antioxidative activity of hazelnuts (Corylus avellana L.). J Food Sci 76, S14-S19.

92. Villarreal-Lozoya JE, Lombardini L \& Cisneros-Zevallos L (2009) Electron-beam irradiation effects on phytochemical constituents and antioxidant capacity of pecan kernels [Carya illinoinensis (Wangenh.) K. Koch] during storage. J Agric Food Chem 57, 10732-10739.

93. Sze-Tao KWC, Schrimpf JE, Teuber SS, et al. (2001) Effects of processing and storage on walnut (Juglans regia $\mathrm{L}$ ) tannins. J Sci Food Agric 81, 1215-1222.

94. Chen CY \& Blumberg JB (2008) In vitro activity of almond skin polyphenols for scavenging free radicals and inducing quinone reductase. J Agric Food Chem 56, 4427-4434. 
95. Ghirardello D, Prosperini S, Zeppa G, et al. (2010) Phenolic acid profile and antioxidant capacity of hazelnut (Corylus avellana L.) kernels in different solvent systems. J Food Nutr Res 49, 195-205.

96. Nijveldt RJ, van Nood E, van Hoorn DE, et al. (2001) Flavonoids: a review of probable mechanisms of action and potential applications. Am J Clin Nutr 74, 418-425.

97. Jenkins DJA, Kendall CWC, Marchie A, et al. (2008) Almonds reduce biomarkers of lipid peroxidation in older hyperlipidemic subjects. J Nutr 138, 908-913.

98. Zern TL \& Fernandez ML (2005) Cardioprotective effects of dietary polyphenols. J Nutr 135, 2291-2294.

99. Hu FB, Stampfer MJ, Manson JE, et al. (1998) Frequent nut consumption and risk of coronary heart disease in women: prospective cohort study. BMJ 317, 1341-1345.

100. Albert CM, Gaziano JM, Willett WC, et al. (2002) Nut consumption and decreased risk of sudden cardiac death in the Physicians' Health Study. Arch Intern Med 162, $1382-1387$.

101. Ellsworth JL, Kushi LH \& Folsom AR (2001) Frequent nut intake and risk of death from coronary heart disease and all causes in postmenopausal women: the Iowa Women's Health Study. Nutr Metab Cardiovasc Dis 11, 372-377.

102. Kushi LH, Folsom AR, Prineas RJ, et al. (1996) Dietary antioxidant vitamins and death from coronary heart disease in postmenopausal women. $N$ Engl J Med 334, $1156-1162$.

103. Fraser GE (1999) Associations between diet and cancer, ischemic heart disease, and all-cause mortality in nonHispanic white California Seventh-Day Adventists. Am J Clin Nutr 70, Suppl. 3, 532S-538S.

104. Fraser GE (1999) Nut consumption, lipids, and risk of a coronary event. Clin Cardiol 22, Suppl. 7, III11-III115.

105. Fraser GE \& Shavlik DJ (1997) Risk factors for all-cause and coronary heart disease mortality in the oldest-old. The Adventist Health Study. Arch Intern Med 157, 2249-2258.

106. Fraser GE, Sumbureru D, Pribis P, et al. (1997) Association among health habits, risk factors, and all-cause mortality in a black California population. Epidemiology 8, 168-174.

107. Hu FB \& Stampfer MJ (1999) Nut consumption and risk of coronary heart disease: a review of epidemiologic evidence. Curr Atheroscler Rep 1, 204-209.

108. Kris-Etherton PM, Zhao G, Binkoski AE, et al. (2001) The effects of nuts on coronary heart disease risk. Nutr Rev 59, 103-111.

109. Djousse L, Rudich T \& Gaziano JM (2009) Nut consumption and risk of hypertension in US male physicians. Clin Nutr 28, $10-14$.

110. Jiang R, Manson JE, Stampfer MJ, et al. (2002) Nut and peanut butter consumption and risk of type 2 diabetes in women. JAMA 288, 2554-2560.

111. Mantzoros CS, Williams CJ, Manson JE, et al. (2006) Adherence to the Mediterranean dietary pattern is positively associated with plasma adiponectin concentrations in diabetic women. Am J Clin Nutr 84, 328-335.

112. Li TY, Brennan AM, Wedick NM, et al. (2009) Regular consumption of nuts is associated with a lower risk of cardiovascular disease in women with type 2 diabetes. J Nutr 139, 1333-1338.

113. Jiang R, Jacobs DR Jr, Mayer-Davis E, et al. (2006) Nut and seed consumption and inflammatory markers in the multiethnic study of atherosclerosis. Am J Epidemiol 163, 222-231.

114. Nettleton JA, Steffen LM, Mayer-Davis EJ, et al. (2006) Dietary patterns are associated with biochemical markers of inflammation and endothelial activation in the Multi-
Ethnic Study of Atherosclerosis (MESA). Am J Clin Nutr 83, 1369-1379.

115. Danesh J, Wheeler JG, Hirschfield GM, et al. (2004) C-reactive protein and other circulating markers of inflammation in the prediction of coronary heart disease. $N$ Engl J Med 350, 1387-1397.

116. Luc G, Bard JM, Juhan-Vague I, et al. (2003) C-reactive protein, interleukin-6, and fibrinogen as predictors of coronary heart disease: the PRIME Study. Arterioscler Thromb Vasc Biol 23, 1255-1261.

117. Pai JK, Pischon T, Ma J, et al. (2004) Inflammatory markers and the risk of coronary heart disease in men and women. $N$ Engl J Med 351, 2599-2610.

118. Gopinath B, Buyken AE, Flood VM, et al. (2011) Consumption of polyunsaturated fatty acids, fish, and nuts and risk of inflammatory disease mortality. Am J Clin Nutr 93, 1073-1079.

119. Mukuddem-Petersen J, Oosthuizen W \& Jerling JC (2005) A systematic review of the effects of nuts on blood lipid profiles in humans. J Nutr 135, 2082-2089.

120. Griel AE \& Kris-Etherton PM (2006) Tree nuts and the lipid profile: a review of clinical studies. BrJ Nutr 96, Suppl. 2, S68-S78.

121. Mercanligil SM, Arslan P, Alasalvar C, et al. (2007) Effects of hazelnut-enriched diet on plasma cholesterol and lipoprotein profiles in hypercholesterolemic adult men. Eur $J$ Clin Nutr 61, 212-220.

122. Tey SL, Brown RC, Chisholm AW, et al. (2011) Effects of different forms of hazelnuts on blood lipids and -tocopherol concentrations in mildly hypercholesterolemic individuals. Eur J Clin Nutr 65, 117-124.

123. Sheridan MJ, Cooper JN, Erario M, et al. (2007) Pistachio nut consumption and serum lipid levels. J Am Coll Nutr 26, 141-148.

124. Griel AE, Cao Y, Bagshaw DD, et al. (2008) A macadamia nut-rich diet reduces total and LDL-cholesterol in mildly hypercholesterolemic men and women. J Nutr $\mathbf{1 3 8}$ 761-767.

125. Maranhao PA, Kraemer-Aguiar LG, Oliveira CL, et al. (2011) Brazil nuts intake improves lipid profile, oxidative stress and microvascular function in obese adolescents: a randomized controlled trial. Nutr Metab 28, 32 .

126. Sabate J, Oda K \& Ros E (2010) Nut consumption and blood lipid levels: a pooled analysis of 25 intervention trials. Arch Intern Med 170, 821-827.

127. Segura R, Javierre C, et al. (2006) Other relevant components of nuts: phytosterols, folate and minerals. $\mathrm{Br} J$ Nutr 96, Suppl. 2, S36-S44.

128. Estruch R, Martínez-González MA, Corella D, et al. (2006) Effects of a Mediterranean-style diet on cardiovascular risk factors: a randomized trial. Ann Intern Med 145, 1-11.

129. Ros E, Nunez I, Perez-Heras A, et al. (2004) A walnut diet improves endothelial function in hypercholesterolemic subjects: a randomized crossover trial. Circulation 109, 1609-1614

130. Cortes B, Nunez I, Cofan M, et al. (2006) Acute effects of high-fat meals enriched with walnuts or olive oil on postprandial endothelial function. J Am Coll Cardiol $\mathbf{4 8}$ 1666-1671.

131. Sari I, Baltaci Y, Bagci C, et al. (2010) Effect of pistachio diet on lipid parameters, endothelial function, glucose, inflammation and oxidative status: a prospective study. J Vasc Res $\mathbf{4 7}, 16$.

132. Garg ML, Blake RJ, Wills RB, et al. (2007) Macadamia nut consumption modulates favourably risk factors for coronary artery disease in hypercholesterolemic subjects. Lipids 42, 583-587. 
133. Rajaram S, Connell KM \& Sabate J (2010) Effect of almondenriched high-monounsaturated fat diet on selected markers of inflammation: a randomised, controlled, crossover study. Br J Nutr 103, 907-912.

134. Zhao G, Etherton TD, Martin KR, et al. (2004) Dietary $\alpha$-linolenic acid reduces inflammatory and lipid cardiovascular risk factors in hypercholesterolemic men and women. J Nutr 134, 2991-2997.

135. Zhao G, Etherton TD, Martin KR, et al. (2007) Dietary $\alpha$-linolenic acid inhibits proinflammatory cytokine production by peripheral blood mononuclear cells in hypercholesterolemic subjects. Am J Clin Nutr 85, 385-391.

136. Mukuddem-Petersen J, Stonehouse Oosthuizen W, Jerling JC, et al. (2007) Effects of a high walnut and high cashew nut diet on selected markers of the metabolic syndrome: a controlled feeding trial. Br J Nutr 97, 1144-1153.

137. Carlsen M, Halvorsen B, Holte K, et al. (2010) The total antioxidant content of more than 3100 foods, beverages, spices, herbs and supplements used worldwide. Nutr J 9, 3 .

138. Mermelstein NH (2010) Dealing with antioxidant assay issues. Food Technol 5, 72-76.

139. Lopez-Uriarte P, Bullo M, Casas-Agustench P, et al. (2009) Nuts and oxidation: a systematic review. Nutr Rev 67, 497-508.

140. Ros E (2009) Nuts and novel biomarkers of cardiovascular disease. Am J Clin Nutr 89, 1649S-1656S.

141. Iwamoto M, Imaizumi K, Sato M, et al. (2002) Serum lipid profiles in Japanese women and men during consumption of walnuts. Eur J Clin Nutr 56, 629-637.

142. Muñoz S, Merlos M, Zambón D, et al. (2001) Walnutenriched diet increases the association of LDL from hypercholesterolemic men with human HepG2 cells. J Lipid Res 42, 2069-2076.

143. Zambón D, Sabaté J, Muñoz S, et al. (2000) Substituting walnuts for monounsaturated fat improves the serum lipid profile of hypercholesterolemic men and women. A randomized crossover trial. Ann Intern Med 132, 538-546.

144. Tapsell LC, Gillen LJ, Patch CS, et al. (2004) Including walnuts in a low-fat/modified-fat diet improves HDL cholesterol-to-total cholesterol ratios in patients with type 2 diabetes. Diabetes Care 27, 2777-2783.

145. Davis L, Stonehouse W, Loots du T, et al. (2007) The effects of high walnut and cashew nut diets on the antioxidant status of subjects with metabolic syndrome. Eur $J$ Nutr 46, 155-164.

146. McKay DL, Chen CY, Yeum KJ, et al. (2010) Chronic and acute effects of walnuts on antioxidant capacity and nutritional status in humans: a randomized, cross-over pilot study. Nutr J 9, 21.

147. Canales A, Benedi J, Nus M, et al. (2007) Effect of walnut-enriched restructured meat in the antioxidant status of overweight/obese senior subjects with at least one extra CHD-risk factor. J Am Coll Nutr 26, 225-232.

148. Nus M, Frances F, Librelotto J, et al. (2007) Arylesterase activity and antioxidant status depend on PON1-Q192R and PON1-L55M polymorphisms in subjects with increased risk of cardiovascular disease consuming walnut-enriched meat. J Nutr 137, 1783-1788.

149. Fito M, Guxens M, Corella D, et al. (2007) Effect of a traditional Mediterranean diet on lipoprotein oxidation: a randomized controlled trial. Arch Intern Med 167, 1195-1203.

150. Haddad E, Jambazian P, Karunia M, et al. (2006) A pecan-enriched diet increases $\gamma$-tocopherol/cholesterol and decreases thiobarbituric acid reactive substances in plasma of adults. Nutr Res 26, 397-402.

151. Durak I, Koksal I, Kacmaz M, et al. (1999) Hazelnut supplementation enhances plasma antioxidant potential and lowers plasma cholesterol levels. Clin Chim Acta 284, $113-115$.

152. Yucesan FB, Orem A, Kural BV, et al. (2010) Hazelnut consumption decreases the susceptibility of LDL to oxidation, plasma oxidized LDL level and increases the ratio of large/small LDL in normolipidemic healthy subjects. Anadolu Kardiyoloji Dergisi 10, 28-35.

153. Kocyigit A, Koylu AA \& Keles H (2006) Effects of pistachio nuts consumption on plasma lipid profile and oxidative status in healthy volunteers. Nutr Metab Cardiovasc Dis 16, 202-209.

154. Jalali-Khanabadi BA, Mozaffari-Khosravi H \& Parsaeyan N (2010) Effects of almond dietary supplementation on coronary heart disease lipid risk factors and serum lipid oxidation parameters in men with mild hyperlipidemia. J Altern Complement Med 16, 1279-1283.

155. Jenkins DJ, Kendall CW, Marchie A, et al. (2008) Almonds reduce biomarkers of lipid peroxidation in older hyperlipidemic subjects. J Nutr 138, 908-913.

156. Jenkins DJ, Kendall CW, Marchie A, et al. (2002) Dose response of almonds on coronary heart disease risk factors: blood lipids, oxidized low-density lipoproteins, lipoprotein(a), homocysteine, and pulmonary nitric oxide: a randomized, controlled, crossover trial. Circulation 106, 1327-1332.

157. Stockler-Pinto MB, Mafra D, Farage NE, et al. (2010) Effect of Brazil nut supplementation on the blood levels of selenium and glutathione peroxidase in hemodialysis patients. Nutrition 26, 1065-1069.

158. Thomson CD, Chisholm A, McLachlan SK, et al. (2008) Brazil nuts: an effective way to improve selenium status. Am J Clin Nutr 87, 379-384.

159. Jenkins DJ, Kendall CW, Josse AR, et al. (2006) Almonds decrease postprandial glycemia, insulinemia, and oxidative damage in healthy individuals. J Nutr 136, 2987-2992.

160. Lopez-Uriarte P, Nogues R, Saez G, et al. (2010) Effect of nut consumption on oxidative stress and the endothelial function in metabolic syndrome. Clin Nutr 29, 373-380.

161. Jia X, Li N, Zhang W, et al. (2006) A pilot study on the effects of almond consumption on DNA damage and oxidative stress in smokers. Nutr Cancer 54, 179-183.

162. Li N, Jia X, Chen CY, et al. (2007) Almond consumption reduces oxidative DNA damage and lipid peroxidation in male smokers. J Nutr 137, 2717-2722.

163. Kay CD, Gebauer SK, West SG, et al. (2010) Pistachios increase serum antioxidants and lower serum oxidizedLDL in hypercholesterolemic adults. J Nutr 140, 1093-1098.

164. Torabian S, Haddad E, Rajaram S, et al. (2009) Acute effect of nut consumption on plasma total polyphenols, antioxidant capacity and lipid peroxidation. J Hum Nutr Diet 22, $64-71$.

165. Bartolome B, Monagas M, Garrido I, et al. (2010) Almond (Prunus dulcis (Mill.) D.A. Webb) polyphenols: from chemical characterization to targeted analysis of phenolic metabolites in humans. Arch Biochem Biophys 501, $124-133$.

166. Teets AS, Sundararaman M \& Were LM (2008) Electron beam irradiated almond skin powder inhibition of lipid oxidation in cooked salted ground chicken breast. Food Chem 111, 934-941.

167. Mandalari G, Faulks RM, Bisignano C, et al. (2010) In vitro evaluation of the prebiotic properties of almond skins (Amygdalus communis L.). FEMS Microbiol Lett 304, 116-122

168. Piironen V, Toivo J, Puupponen-Pimiä R, et al. (2003) Plant sterols in vegetables, fruits and berries. J Sci Food Agric $\mathbf{8 3}$, $330-337$. 
169. Jeong TM, Itoh T, Tamura T, et al. (1975) Analysis of methylsterol fractions from twenty vegetable oils. Lipids 10, 634-640.

170. Phillips KM, Ruggio DM \& Ashraf-Khorassani M (2005) Phytosterol composition of nuts and seeds commonly consumed in the United States. J Agric Food Chem 53, 9436-9445.

171. Jimenez-Escrig A, Santos-Hidalgo AB \& Saura-Calixto F (2006) Common sources and estimated intake of plant sterols in the Spanish diet. J Agric Food Chem 54, 3462-3471.

172. Kaijser A, Dutta P \& Savage G (2000) Oxidative stability and lipid composition of macadamia nuts grown in New Zealand. Food Chem 71, 67-70.

173. Liggins J, Bluck LJ, Runswick S, et al. (2000) Daidzein and genistein content of fruits and nuts. $J$ Nutr Biochem 11, 326-331.

174. Andrade EHA, Maia JGS, Streich R, et al. (1999) Seed composition of Amazonian lecythidaceae species: part 3 in the series "Studies of edible Amazonian plants". J Food Comp Anal 12, 37-51.

175. Jeong T, Itoh T, Tamura T, et al. (1974) Analysis of sterol fractions from twenty vegetable oils. Lipids 9, 921-927.

176. Toschi TG, Caboni MF, Penazzi G, et al. (1993) A study on cashew nut oil composition. J Am Oil Chem Soc 70, 1017-1020.

177. Alasalvar C, Amaral JS, Satır G, et al. (2009) Lipid characteristics and essential minerals of native Turkish hazelnut varieties (Corylus avellana L.). Food Chem 113, 919-925.

178. Alasalvar C, Amaral JS \& Shahidi F (2006) Functional lipid characteristics of Turkish Tombul hazelnut (Corylus avellana L.). J Agric Food Chem 54, 10177-10183.

179. Azadmard-Damirchi S \& Dutta PC (2009) A single step solid-phase extraction method for complete separation of sterol oxidation products in food lipids. J Chromatogr $A$ 1216, 36-42.

180. Bada JC, León-Camacho M, Prieto M, et al. (2004) Characterization of oils of hazelnuts from Asturias, Spain. Eur J Lipid Sci Technol 106, 294-300.

181. Benitez-Sanchez PL, Lean-Camacho M \& Aparicio R (2003) A comprehensive study of hazelnut oil composition with comparisons to other vegetable oils, particularly olive oil. Eur Food Res Technol 218, 13-19.

182. Bernardo-Gil MG, Grenha J, Santos J, et al. (2002) Supercritical fluid extraction and characterisation of oil from hazelnut. Eur J Lipid Sci Technol 104, 402-409.

183. Crews C, Hough P, Godward J, et al. (2005) Study of the main constituents of some authentic hazelnut oils. J Agric Food Chem 53, 4843-4852.

184. Damirchi S, Savage G \& Dutta P (2005) Sterol fractions in hazelnut and virgin olive oils and 4,4'-dimethylsterols as possible markers for detection of adulteration of virgin olive oil. J Am Oil Chem Soc 82, 717-725.

185. Karabulut I, Topcu A, Yorulmaz A, et al. (2005) Effects of the industrial refining process on some properties of hazelnut oil. Eur J Lipid Sci Technol 107, 476-480.

186. Parcerisa J, Richardson DG, Rafecas M, et al. (1998) Fatty acid, tocopherol and sterol content of some hazelnut varieties (Corylus avellana L.) harvested in Oregon (USA). J Chromatogr A 805, 259-268.

187. Savage G, McNeil D \& Dutta P (1997) Lipid composition and oxidative stability of oils in hazelnuts (Corylus avellana L.) grown in New Zealand. J Am Oil Chem Soc 74, 755-759.

188. Quinn L \& Tang H (1996) Antioxidant properties of phenolic compounds in macadamia nuts. J Am Oil Chem Soc $\mathbf{7 3}$ $1585-1588$.

189. Nasri N, Fady B \& Triki S (2007) Quantification of sterols and aliphatic alcohols in Mediterranean stone pine (Pinus pinea L.) populations. J Agric Food Chem 55, 2251-2255.

190. Zadernowski R, Naczk M \& Czaplicki S (2009) Chemical composition of Pinus sibirica nut oils. Eur J Lipid Sci Technol 111, 698-704.

191. Tomaino A, Martorana M, Arcoraci T, et al. (2010) Antioxidant activity and phenolic profile of pistachio (Pistacia vera $\mathrm{L}$., variety Bronte) seeds and skins. Biochimie $\mathbf{9 2}$ $1115-1122$.

192. Yildiz M, Türkan GS \& Özdemir M (1998) Oil composition of pistachio nuts (Pistacia vera L.) from Turkey. Lipid/Fett 100, 84-86.

193. Mahoney N \& Molyneux RJ (2004) Phytochemical inhibition of aflatoxigenicity in Aspergillus flavus by constituents of walnut (Juglans regia). J Agric Food Chem 52, 1882-1889.

194. Verardo V, Bendini A, Cerretani L, et al. (2009) Capillary gas chromatography analysis of lipid composition and evaluation of phenolic compounds by micellar electrokinetic chromatography in Italian walnut (Juglans regia L.): irrigation and fertilization influence. J Food Qual 32, 262-281.

195. Crews C, Hough P, Godward J, et al. (2005) Study of the main constituents of some authentic walnut oils. J Agric Food Chem 53, 4853-4860.

196. Oliveira R, Rodrigues MF \& Gabriela Bernardo-Gil M (2002) Characterization and supercritical carbon dioxide extraction of walnut oil. J Am Oil Chem Soc 79, 225-230.

197. Schwartz H, Ollilainen V, Piironen V, et al. (2008) Tocopherol, tocotrienol and plant sterol contents of vegetable oils and industrial fats. J Food Comp Anal 21, 152-161.

198. Harland BF, Smikle-Williams S \& Oberleas D (2004) High performance liquid chromatography analysis of phytate (IP6) in selected foods. J Food Comp Anal 17, 227-233.

199. Fang F, Ho C-T, Sang S, et al. (2005) Determination of sphingolipids in nuts and seeds by a single quadrupole liquid chromatography-mass spectrometery method. $J$ Food Lipids 12, 327-343.

200. Chen Q (2004) Determination of phytic acid and inositol pentakisphosphates in foods by high-performance ion chromatography. J Agric Food Chem 52, 4604-4613.

201. Kubo I, Komatsu S \& Ochi M (1986) Molluscicides from the cashew Anacardium occidentale and their large-scale isolation. J Agric Food Chem 34, 970-973.

202. Cheikh-Rouhou S, Hentati B, Besbes S, et al. (2006) Chemical composition and lipid fraction characteristics of aleppo pine (Pinus halepensis Mill.) seeds cultivated in Tunisia. Food Sci Technol Int 12, 407-415.

203. Saitta M, Giuffrida D, La Torre GL, et al. (2009) Characterisation of alkylphenols in pistachio (Pistacia vera L.) kernels. Food Chem 117, 451-455. 